\title{
Basic processes in reading: A critical review of pseudohomophone effects in reading aloud and a new computational account
}

\author{
MICHAEL REYNOLDS and DEREK BESNER \\ University of Waterloo, Waterloo, Ontario, Canada
}

\begin{abstract}
There are pervasive lexical influences on the time that it takes to read aloud novel letter strings that sound like real words (e.g., brane from brain). However, the literature presents a complicated picture, given that the time taken to read aloud such items is sometimes shorter and sometimes longer than a control string (e.g., frane) and that the time to read aloud is sometimes affected by the frequency of the base word and other times is not. In the present review, we first organize these data to show that there is considerably more consistency than has previously been acknowledged. We then consider six different accounts that have been proposed to explain various aspects of these data. Four of them immediately fail in one way or another. The remaining two accounts may be able to explain these findings, but they either make counterintuitive assumptions or invoke a novel mechanism solely to explain these findings. A new account is advanced that is able to explain all of the effects reviewed here and has none of the problems associated with the other accounts. According to this account, different types of lexical knowledge are used when pseudohomophones and nonword controls are read aloud in mixed and pure lists. This account is then implemented in Coltheart, Rastle, Perry, Langdon, and Ziegler's (2001) dual route cascaded model in order to provide an existence proof that it accommodates all of the effects, while retaining the ability to simulate three standard effects seen in nonword reading aloud.
\end{abstract}

A thorough understanding of the processes underlying the seemingly effortless act of reading a single letter string aloud would be a considerable achievement, in view of the fact that reading is a major cognitive skill. One contrast that has arisen in the study of reading aloud is the distinction between lexical and sublexical processes. Sublexical influences on word reading (e.g., reading words aloud) have been the topic of considerable research (e.g., the so called regularity effect; see Roberts, Rastle, Coltheart, \& Besner, 2003, for a recent investigation that pits four different computational accounts against each other). Considerably less research has investigated lexical influences on novel word reading (e.g., reading nonwords aloud). Two lines of research have been pursued. One line concerns the effect of word neighbors (e.g., crane) on nonword reading aloud (e.g., clane) and has received little attention. The only three experimental papers on this topic with skilled readers of English are those by McCann and Besner (1987) and Reynolds and Besner (2004; see also Weekes, 1997). A related line of investigation concerns how nonwords that sound like words (e.g., brane) are influenced by the base word (brain) in reading aloud has received considerably more attention.

This research was supported by a doctoral fellowship from the Natural Sciences and Engineering Research Council of Canada to M.R. and by Grant A0998 to D.B. We thank David Plaut, Max Coltheart, and particularly Steve Lupker for constructive comments on earlier versions of the manuscript. Correspondence concerning this article should be addressed to M. Reynolds or D. Besner, Department of Psychology, University of Waterloo, Waterloo, ON, N2L 3G1 Canada (e-mail: mg2reynolds@ uwaterloo.ca or dbesner@watarts.uwaterloo.ca).
Here, we address the simple act of reading pseudohomophones (nonwords that sound like words-e.g., brane from brain) and their controls (e.g., frane) aloud. A number of well-replicated effects have been reported since the first investigation of pseudohomophone reading aloud in intact skilled readers. Their interpretation, however, has been associated with considerable controversy. In addition, recent research has reported several counterintuitive findings. At present, there is no broadly accepted account of all these effects. In the present article, we briefly review six critical findings in this literature and six different accounts of these findings, and discuss their limitations. We also report a new experiment that replicates Borowsky, Owen, and Masson's (2002) novel demonstration of a pseudohomophone disadvantage and the modulation of this pseudohomophone disadvantage and base word frequency effect by list order. We then provide a new account of these six findings and report a successful computational instantiation of this account. We conclude that processing is considerably more dynamic than is widely believed and suggest several lines of investigation that merit further consideration.

\section{THE FACTS}

Currently, there are six effects that any successful account needs to explain. Three of these effects are well established in the literature (although not widely understood as such). These are (1) the pseudohomophone advantage and (2) the accompanying absence of a base word frequency effect when pseudohomophones and their controls 
are randomly intermixed (mixed list) and (3) the presence of a base word frequency effect in pure list reading aloud. The remaining three effects-(4) the conjunction of a pseudohomophone disadvantage and the presence of a base word frequency effect in a pure list when the pseudohomophones are read aloud before their nonword controls and the conjunction of (5) a reduced pseudohomophone disadvantage and (6) a reduced base word frequency effect when pseudohomophones are read aloud in a pure list after their nonword controls-have only recently been reported. We will discuss each of these effects in turn and will report a new experiment that replicates and extends our understanding of the latter three effects.

\section{The Pseudohomophone Advantage in a Mixed List}

McCann and Besner (1987) were the first to report that intact skilled readers read aloud pseudohomophones (e.g., brane) more quickly than they do control nonwords (e.g., frane) when the pseudohomophones and the controls are randomly mixed together in a single list. This pseudohomophone advantage has since been replicated a number of times (Borowsky et al., 2002 [two experiments]; Grainger, Spinelli, \& Ferrand, 2000; Herdman, LeFevre, \& Greenham, 1996 [two experiments]; Marmurek \& Kwantes, 1996 [three experiments]; Taft \& Russell, 1992).

\section{The Absence of a Base Word Frequency Effect for Pseudohomophone Reading Aloud in a Mixed List}

It is well known that the more frequently a word is encountered in print, the more quickly it is read aloud (e.g., Forster \& Chambers, 1973). McCann and Besner (1987) also investigated whether the time it takes to read aloud a pseudohomophone (e.g., brane) is affected by how frequently their base words (e.g., brain) has been encountered in print. They reported a null base word frequency effect for pseudohomophones when these were randomly mixed with their nonword controls. That is, reading the pseudohomophones aloud was not affected by how frequently the base word had been encountered. ${ }^{1}$

This report of a null effect has been contested. Taft and Russell (1992) argued that McCann and Besner (1987) made a Type II error due to poor stimulus selection. They also reported an experiment of their own in which pseudohomophones produced a base word frequency effect in mixed lists. Subsequent research has suggested that McCann and Besner's results do not constitute a Type II error. Marmurek and Kwantes (1996) have reported three demonstrations of a null base word frequency effect for pseudohomophones in mixed lists (despite their use of Taft and Russell's items in one experiment). Furthermore, Herdman et al. (1996) noted that word frequency was confounded with other orthographic factors in Taft and Russell's stimuli, and they reported no base word frequency effect when these factors were properly controlled. Finally, two other laboratories have reported a null base word frequency effect with different stimulus sets (Borowsky et al., 2002; Grainger et al., 2000). In summary, the published data are most consistent with the conclusion that there is no base word frequency effect on reading aloud when pseudohomophones are randomly mixed with control nonwords.

\section{The Presence of a Base Word Frequency Effect for Reading Aloud a Pure List}

Marmurek and Kwantes (1996) assessed whether the null base word frequency effect observed with mixed lists was a consequence of list structure. They therefore investigated whether a base word frequency effect is observed when pseudohomophones are read aloud in a pure list. Indeed, this is what they found in three experiments. The presence of a pseudohomophone base word frequency effect on reading aloud a pure list has subsequently been replicated in other laboratories (Borowsky et al., 2002; Borowsky, Phillips, \& Owen, 2003; Grainger et al., 2000).

\section{The Pseudohomophone Disadvantage in Pure Lists}

The remaining phenomena concern how pseudohomophones and nonword controls are read aloud in pure lists. Although Marmurek and Kwantes (1996) and Grainger et al. (2000) investigated pseudohomophone reading aloud in pure and mixed lists, they did not compare the time to read pseudohomophones aloud in a pure list with that for nonword controls in a pure list. In their Experiment 1, Marmurek and Kwantes had subjects read aloud both pseudohomophones in a pure list and nonwords (mixed with pseudohomophones). The pseudohomophones in the pure list were read aloud $77 \mathrm{msec}$ more slowly than the nonword controls. Marmurek and Kwantes did not analyze this contrast, but our analysis shows it to be significant $[t(15)=$ $4.38, p<.001$, equal variance assumed]. With the exception of Borowsky et al. (2002), this effect has been ignored in the literature. It is difficult to draw any conclusions from Marmurek and Kwantes's remaining experiments, because list context was manipulated between subjects.

To date, Borowsky et al. (2002) are the only investigators to explicitly compare reading aloud performance for pseudohomophones and nonword controls when those are read aloud in pure lists. They used the stimulus sets from Herdman et al. (1996), McCann and Besner (1987), and Seidenberg, Peterson, MacDonald, and Plaut (1996) and one of their own. Three of the four lists produced a pseudohomophone disadvantage in which pseudohomophones took longer to read aloud than nonword controls. That is, unlike the mixed list situation, where it has been repeatedly demonstrated that pseudohomophones are read aloud more quickly than nonword controls, in a pure list pseudohomophones are read aloud more slowly than nonword controls. This is remarkable in that if the pseudohomophone disadvantage is strategic, it is an instance in which "strategy" hinders performance.

\section{The Modulation of the Pseudohomophone Disadvantage by List Order}

Borowsky et al. (2002) also manipulated the order in which subjects read aloud the pseudohomophones and nonword controls in pure lists. The pseudohomophone dis- 
advantage was smaller for three of the four stimulus sets when the pseudohomophones were read aloud after the nonword controls. Seidenberg et al.'s (1996) items were the exception, yielding a larger disadvantage when the pseudohomophones were read aloud after the nonword controls. Thus, at least for three of the four lists, the data are consistent with a modulation of the size of the pseudohomophone disadvantage by list order, so that it is larger when pseudohomophones are read aloud before nonword controls.

\section{The Modulation of the Base Word Frequency Effect by List Order}

Borowsky et al. (2002) reported that for two of the four stimulus sets, the base word frequency effect was smaller when pseudohomophones were read aloud after nonword controls. In contrast, McCann and Besner's (1987) items yielded a larger base word frequency effect when pseudohomophones were read aloud after nonword controls, and Herdman et al.'s (1996) items yielded no base word frequency effect at all. Although it appears that list order affects the size of the base word frequency effect, more data are clearly needed to put this finding on a stronger footing.

\section{A NEW EXPERIMENT}

The importance of Borowsky et al.'s (2002) findings for accounts of pseudohomophone reading aloud cannot be overstated. At the time of publication, there were no accounts of pseudohomophone reading aloud that explicitly predicted either a pseudohomophone disadvantage or its modulation by list order. However, as was noted above, there is a substantial amount of variability in Borowsky et al.'s (2002) data across stimulus sets, especially with respect to the modulation of base word frequency effects by list order. Indeed, although the overall pattern of data reported by Borowsky et al. (2002) consists of a pseudohomophone disadvantage and base word frequency effect when pseudohomophones are read aloud before nonword controls and a reduced pseudohomophone disadvantage and a null base word frequency effect when pseudohomophones are read aloud after nonword controls, no single stimulus set produces all of these effects. It is not surprising, therefore, that the modulation of the pseudohomophone disadvantage and base word frequency effect has met with some skepticism.

It is unclear why there is so much variability in Borowsky et al.'s (2002) data. One possibility is that their experiments did not have sufficient power to demonstrate all four effects for each list (unfortunately, they did not report the error terms in any of their analyses). Another possible source of variability may be a consequence of how the data were analyzed. Borowsky et al. (2002) measured base word frequency effects by using linear regression. However, they did not report excluding any observations that were outliers with respect to the best-fitting line or those stimuli that had a disproportionately large influence on the regression coefficients (e.g., leverage; see Hoaglin \& Welsch, 1978).
The purpose of the present experiment was to attempt to replicate and expand on Borowsky et al.'s (2002) report of the modulation of the pseudohomophone disadvantage and base word frequency effect as a function of list order. We improve upon Borowsky et al.'s (2002) design by including a delayed reading aloud condition. There are two reasons for including this condition. First, previous studies in which the pseudohomophone advantage has been examined have contrasted online and delayed reading aloud times, out of concern that part of the advantage may arise from differences in ease of articulation (McCann \& Besner, 1987; Taft \& Russell, 1992). Consistent with this possibility, virtually all of the studies in the literature have reported a reduced pseudohomophone advantage in the delayed reading aloud condition. If pseudohomophones have an articulatory advantage over nonword controls (as measured during delayed reading aloud), a null difference between pseudohomophones and nonword controls during online reading aloud would indicate that generating a pronunciation for the pseudohomophones is actually slowed, relative to the nonword controls. Therefore, the critical evidence for a lexically driven pseudohomophone disadvantage is a larger disadvantage during online reading aloud, as compared with delayed reading aloud. Similarly, the critical evidence for a lexically driven base word frequency effect is a larger frequency effect during online reading aloud, as compared with delayed reading aloud.

Second, the presence of a pseudohomophone disadvantage when pseudohomophones are read aloud first could be ascribed to nonspecific practice at nonword reading aloud. For example, it is possible that reading aloud time simply decreases over blocks. This can produce a lexicality $\times$ list order interaction. If the list order effects observed in online reading aloud are due simply to nonspecific practice effects, online reading aloud and delayed reading aloud should yield similar effects. Given this, the critical test for slowed pseudohomophone processing, relative to nonword controls, is the contrast between online and delayed reading aloud conditions. If the reduction in the size of the pseudohomophone disadvantage as a function of list order is due, in part, to a decrease in the use of lexical knowledge for the pseudohomophones, there ought to be an accompanying decrease in the size of the base word frequency effect for the pseudohomophones when they are read aloud second.

\section{Method}

\section{Subjects}

Thirty-two undergraduates from the University of Waterloo participated in the experiment; each was paid $\$ 4$ for his or her participation. All the subjects reported normal or corrected-to-normal vision and were native English speakers.

\section{Apparatus}

Stimulus presentation was controlled by a Pentium IV $1.8-\mathrm{GHz}$ computer running E-Prime 1.1. Vocal responses were collected using a Plantronics LS1 microphone headset and a voice key assembly. The stimuli were displayed on a 17 -in. ADI Microscan monitor. 


\section{Stimuli}

The stimuli consisted of 45 high-frequency and 45 low-frequency pseudohomophones and 90 matched nonword controls. Nonword controls were generated by rotating the onsets and rhymes of the pseudohomophones. High- and low-frequency items were matched on initial phoneme. Lists were equated on the number of orthographic neighbors and the number of body neighbors, including the number of body friends and the number of body enemies. Lists were also equated on position-specific and non-position-specific bigram and trigram frequencies, letter length, whammies (Rastle \& Coltheart, 1998), and number of phonological neighbors. A summary of the stimulus characteristics can be seen in Table 1. The stimuli appear in Appendix A.

\section{Procedure}

The subjects read aloud pseudohomophones and nonword controls presented in pure lists, with list order counterbalanced across subjects. The subjects were told that in the pseudohomophone condition, items would sound like a word that they knew and that in the nonword control condition, items would not sound like a word that they knew. The subjects were instructed to read the strings aloud as quickly but as accurately as possible.

A trial began with a fixation marker $(+)$ in the center of the screen for $1,000 \mathrm{msec}$, followed by a blank screen for $500 \mathrm{msec}$. The target was then presented at fixation until a vocal response was made. A blank screen then appeared for $800 \mathrm{msec}$, followed by a single dot presented immediately to the left of fixation. After $400 \mathrm{msec}$, a second dot appeared immediately to the right of the first, followed by a third dot after another $400 \mathrm{msec}$. After another $400 \mathrm{msec}$, the dots were replaced by a set of brackets that enclosed the fixation marker and remained on the screen until the subject read aloud the letter string a second time. The experimenter then coded the response as correct, incorrect (e.g., an extra or deleted phoneme or lexicalization), or spoiled (e.g., a cough, a stutter, or the voice key failed to activate). In addition, the experimenter transcribed the subject's pronunciation on incorrect trials when time permitted.

Each subject received 8 practice trials, followed by 90 experimental trials for each list condition. The stimuli in each list condition were presented in a different randomized order for each subject. All the stimuli were presented in a black 16-point Times Roman font in lowercase letters on a white background.

\section{Results}

Responses classified as incorrect pronunciations $(11.4 \%)$ or voice key failures $(6.9 \%)$ were removed from the reading aloud data prior to the response time (RT) analysis. An error was defined as an utterance that represented a clear mispronunciation (i.e., an extra or deleted phoneme or lexicalization of a nonword) or a pronuncia- tion of a nonword that did not rhyme with the pronunciation required for a pseudohomophone with the same body.

RTs to correct responses were first subjected to a recursive trimming procedure in which the criterion cutoff for outlier removal was established independently for each condition for each subject, by reference to the sample size in that cell (Van Selst \& Jolicœur, 1994). If an item was established as an outlier in either online or delayed reading aloud, this resulted in the removal of both scores. Analysis of the online reading aloud data resulted in the removal of $2.2 \%$ of the correct trials, and analysis of the delayed reading aloud data resulted in the removal of an additional $1.4 \%$ of the correct trials. ${ }^{2}$ The RT and error data can be seen in Table 2 .

\section{Reaction Times}

Lexicality effect: Online reading aloud. For the subject analysis, lexicality effects were assessed using a mixed model ANOVA with list order (pseudohomophones first/nonwords first) as a between-subjects factor and lexicality (pseudohomophone/nonword) as a repeated factor. For the item analysis, lexicality effects were assessed using a mixed model ANOVA with list order as a repeated factor and lexicality as a between-items factor. The analysis yielded a significant interaction between lexicality and list order $\left[F_{1}(1,30)=11.3, M S_{\mathrm{e}}=5,603\right.$, $\left.p<.001 ; F_{2}(1,89)=86.1, M S_{\mathrm{e}}=3,945, p<.001\right]$. When pseudohomophones were read aloud first, there was a significant pseudohomophone disadvantage [pseudohomophones read aloud in Block 1 were $128 \mathrm{msec}$ slower than nonword controls read aloud in Block $2 ; F_{1}(1,30)=$ $14.1, M S_{\mathrm{e}}=5,603, p<.001 ; F_{2}(1,89)=155.2, M S_{\mathrm{e}}=$ $3,945, p<.001]$. When nonword controls were read aloud first, the 2-msec pseudohomophone disadvantage was not significant $(F \mathrm{~s}<1)$.

Lexicality effect: Delayed reading aloud. Analysis of the delayed reading aloud data yielded an interaction between stimulus order and lexicality $\left[F_{1}(1,30)=11.3\right.$, $M S_{\mathrm{e}}=1,433, p<.001 ; F_{2}(1,178)=109.2, M S_{\mathrm{e}}=704$, $p<.001]$. One way this interaction can be understood is as a 31-msec pseudohomophone disadvantage when pseudohomophones were read aloud first $\left[F_{1}(1,30)=5.2, M S_{\mathrm{e}}=\right.$ $\left.1,433, p<.05 ; F_{2}(1,89)=44.9, M S_{\mathrm{e}}=704, p<.001\right]$ and a 33-msec pseudohomophone advantage when non-

Table 1

Summary Statistics for the Pseudohomophones and Nonword Controls

\begin{tabular}{lccc}
\hline \multirow{2}{*}{\multicolumn{1}{c}{ Stimulus Characteristic }} & \multicolumn{2}{c}{ Pseudohomophones } & \\
\cline { 2 - 3 } & High Frequency & Low Frequency & Nonword Controls \\
\hline Number of letters & 4.6 & 4.5 & 4.5 \\
Number of orthographic neighbors & 4.2 & 4.6 & 4.7 \\
Number of phonological neighbors & 15.6 & 17.4 & 18.1 \\
Number of body friends & 4.5 & 5.1 & 5.0 \\
Number of body enemies & 0.5 & 0.7 & 0.6 \\
Number of body neighbors & 5.0 & 5.8 & 5.5 \\
Type bigram frequency (position nonspecific) & 616.2 & 576.6 & 590.4 \\
Type trigram frequency (position nonspecific) & 44.5 & 45.5 & 41.1 \\
Type bigram frequency (position specific) & 91.3 & 82.6 & 89.6 \\
Type trigram frequency (position specific) & 8.9 & 9.5 & 9.2 \\
Base word frequency & 296.6 & 1.2 & - \\
\hline
\end{tabular}


Table 2

Mean Response Times (RTs, in Milliseconds) and Percentages of Error (\%E) for Highand Low-Frequency Pseudohomophones and Nonword Controls as a Function of Online and Delayed Reading Aloud and List Order

\begin{tabular}{|c|c|c|c|c|c|c|}
\hline & \multicolumn{2}{|c|}{ Online } & \multicolumn{2}{|c|}{ Delayed } & \multicolumn{2}{|c|}{ Difference } \\
\hline & RT & $\% \mathrm{E}$ & RT & $\% \mathrm{E}$ & RT & $\% \mathrm{E}$ \\
\hline \multicolumn{7}{|c|}{ Pseudohomophones Read Aloud First } \\
\hline \multicolumn{7}{|l|}{ Lexicality effect } \\
\hline Nonword controls (Block 2) & 707 & 10.5 & 363 & 9.8 & 344 & 0.7 \\
\hline Pseudohomophones (Block 1) & 835 & 12.6 & 394 & 11.8 & 442 & 0.9 \\
\hline Difference & -128 & -2.1 & -31 & -2.0 & -98 & -0.2 \\
\hline \multicolumn{7}{|l|}{ Frequency effect } \\
\hline Low frequency (Block 1) & 876 & 13.1 & 399 & 12.3 & 477 & 0.8 \\
\hline High frequency (Block 1) & 794 & 12.1 & 388 & 11.2 & 406 & 0.9 \\
\hline Difference & 82 & 1.0 & 11 & 1.1 & 71 & -0.1 \\
\hline \multicolumn{7}{|c|}{ Nonwords Read Aloud First } \\
\hline \multicolumn{7}{|l|}{ Lexicality effect } \\
\hline Nonword controls (Block 1) & 750 & 11.7 & 396 & 11.4 & 354 & 0.3 \\
\hline Pseudohomophones (Block 2) & 752 & 11.5 & 364 & 11.2 & 388 & 0.3 \\
\hline Difference & -2 & 0.2 & 33 & 0.2 & -35 & 0.0 \\
\hline \multicolumn{7}{|l|}{ Frequency effect } \\
\hline Low frequency (Block 2) & 767 & 11.4 & 373 & 11.2 & 394 & 0.2 \\
\hline High frequency (Block 2) & 736 & 11.6 & 354 & 11.1 & 382 & 0.5 \\
\hline Difference & 31 & -0.2 & 19 & 0.1 & 12 & -0.3 \\
\hline
\end{tabular}

words were read aloud first $\left[F_{1}(1,30)=6.1, M S_{\mathrm{e}}=1,433\right.$, $\left.p<.05 ; F_{2}(1,89)=70.2, M S_{\mathrm{e}}=704, p<.001\right]$. An alternative interpretation is a main effect of block, where items read aloud in Block 2 were $32 \mathrm{msec}$ faster than items read aloud in Block $1\left[F_{1}(1,30)=11.3, M S_{\mathrm{e}}=1,433\right.$, $\left.p<.001 ; F_{2}(1,178)=100.9, M S_{\mathrm{e}}=762, p<.001\right]$.

Lexicality effect: Online versus delayed reading aloud. Earlier, we noted that a null difference between pseudohomophones and nonword controls in online reading aloud by itself is inconclusive. If pseudohomophones have an articulatory advantage over nonword controls (as measured during delayed reading aloud), a null difference between pseudohomophones and nonword controls during online reading aloud would indicate that generating a pronunciation for the pseudohomophones is slowed, relative to the nonword controls. We also noted that a lexicality $\times$ list order interaction could be interpreted as nonspecific practice at nonword reading aloud. If the list order effects observed in online reading aloud are due to a nonspecific practice effect, online reading aloud and delayed reading aloud should yield similar effects. Given these concerns, we argued that the critical evidence for a lexically driven pseudohomophone disadvantage is a larger disadvantage during online reading aloud, as compared with delayed reading aloud. Similarly, the critical evidence for a lexically driven base word frequency effect is a larger frequency effect during online reading aloud then during delayed reading aloud.

Analysis of the online reading aloud data revealed a pseudohomophone disadvantage when pseudohomophones were read aloud first and a null effect of pseudohomophony when nonwords were read aloud first. In contrast, analysis of the delayed reading aloud data revealed faster reading aloud in Block 2 than in Block 1. This takes the form of a pseudohomophone disadvantage when pseudohomophones are read aloud first and a pseudohomophone advantage when nonwords are read aloud first. It is, therefore, critical that online and delayed reading aloud data be directly compared, to assess whether there is a pseudohomophone disadvantage for both list orders.

A mixed model ANOVA was conducted with lexicality and reading aloud condition (online vs. delayed) as repeated factors and list order as an independent factor for the subject analysis. Lexicality was treated as an independent factor for the item analysis. The three-way interaction was significant $\left[F_{1}(1,30)=3.9, M S_{\mathrm{e}}=1,984\right.$, $\left.p<.06 ; F_{2}(1,89)=20.2, M S_{\mathrm{e}}=2,307, p<.001\right]$. When pseudohomophones were read aloud first, the 128-msec pseudohomophone disadvantage observed in online reading aloud was significantly different from the $31-\mathrm{msec}$ pseudohomophone disadvantage observed during delayed reading aloud $\left[F_{1}(1,15)=12.6, M S_{\mathrm{e}}=1,984, p<\right.$ $\left..001 ; F_{2}(1,89)=81.3, M S_{\mathrm{e}}=2,307, p<.001\right]$. When nonwords were read aloud first, the null 2-msec pseudohomophone disadvantage observed in the online reading aloud condition was also significantly different from the 33-msec pseudohomophone advantage observed during delayed reading aloud $\left[F_{1}(1,15)=4.9, M S_{\mathrm{e}}=1,984\right.$, $\left.p<.05 ; F_{2}(1,89)=7.9, M S_{\mathrm{e}}=2,307, p<.05\right]$.

Base word frequency effect: Online reading aloud. The subject data were analyzed using a mixed model ANOVA with frequency (high vs. low) as a repeated factor and list order as a between-subjects factor. Item data were analyzed with list order as a repeated factor and word frequency as a between-items factor. There was an interaction between base word frequency and list order $\left[F_{1}(1,30)=4.7, M S_{\mathrm{e}}=3,364, p<.05 ; F_{2}(1,88)=10.1\right.$, $\left.M S_{\mathrm{e}}=4,475, p<.001\right]$. There was a significant 82-msec frequency effect when pseudohomophones were read aloud first $\left[F_{1}(1,15)=16.1, M S_{\mathrm{e}}=3,284, p<.001\right.$; 
$\left.F_{2}(1,88)=23.6, M S_{\mathrm{e}}=4,289, p<.001\right]$. When pseudohomophones were read aloud second, the 31-msec frequency effect was not reliable for subjects $\left(F_{1}=1\right)$ but was for items $\left[F_{2}(1,88)=4.6, M S_{\mathrm{e}}=4,289, p<.05\right]$.

Base word frequency effect: Delayed reading aloud. There was a 15 -msec main effect of base word frequency $\left[F_{1}(1,30)=5.8, M S_{\mathrm{e}}=599, p<.05 ; F_{2}(1,88)=5.6\right.$, $\left.M S_{\mathrm{e}}=1,806, p<.05\right]$, and there was no interaction between base word frequency and list order $(F \mathrm{~s}<1)$.

Base word frequency effect: Online versus delayed reading aloud. As was discussed earlier, the critical evidence for a lexically driven base word frequency effect in online reading aloud is a larger frequency effect than in delayed reading aloud. The three-way interaction was significant $\left[F_{1}(1,30)=7.3, M S_{\mathrm{e}}=1,475, p<.001\right.$; $\left.F_{2}(1,178)=10.9, M S_{\mathrm{e}}=2,689, p<.001\right]$. When pseudohomophones were read aloud first, the $82-\mathrm{msec}$ base word frequency effect in the online reading aloud condition was significantly larger than the 11 -msec effect in delayed reading aloud $\left[F_{1}(1,30)=13.2, M S_{\mathrm{e}}=\right.$ $1,475, p<.001 ; F_{2}(1,178)=28.4, M S_{\mathrm{e}}=2,689, p<$ .001]. When pseudohomophones were read aloud second, the 31-msec base word frequency effect in the online reading aloud condition was not significantly different from the 19-msec effect in delayed reading aloud $(F \mathrm{~s}<1)$.

\section{Errors}

Lexicality effect. The subject data were analyzed using a mixed model ANOVA with lexicality as a repeated factor and list order as a between-subjects factor. Item data were analyzed using a mixed model ANOVA with list order as a repeated factor and lexicality as a between-items factor. There was a marginal interaction between these factors for subjects $\left[F_{1}(1,30)=3.1, M S_{\mathrm{e}}=\right.$ $7.1, p<.10$ ], but not for items $\left(F_{2}<1\right)$. When pseudohomophones were read aloud first, $2.1 \%$ more errors were made to pseudohomophones (Block 1) than to nonword controls (Block 2) for subjects $\left[F_{1}(1,15)=5.1, M S_{\mathrm{e}}=\right.$ $7.1, p<.05]$, but not for items $\left(F_{2}<1\right)$. When nonword controls were read aloud first, there was no difference between pseudohomophones in Block 2 and nonword controls in Block $1(\mathrm{Fs}<1)$.

Base word frequency effect. Subject data were analyzed using a mixed model ANOVA with base word frequency (high vs. low) as a repeated factor and list order as a between-subjects factor. Item data were also analyzed using a mixed model ANOVA with list order as a repeated factor and base word frequency as a betweenitems factor. No effects approached significance $\left(F_{\mathrm{S}}<1\right)$.

\section{Discussion}

The purpose of the present experiment was to replicate and extend Borowsky et al.'s (2002) novel observation of a pseudohomophone disadvantage and a base word frequency effect in pure lists and the modulation of these effects by list order. The inclusion of a delayed read- ing aloud condition makes it possible to assess whether lexical processing is slowed during online reading aloud despite the observation of a null pseudohomophone disadvantage. Base word frequency was dichotomized and the RTs trimmed so as to avoid the problems that we noted with Borowsky et al.'s (2002) analyses.

The data show that when pseudohomophones were read aloud first, there was a pseudohomophone disadvantage and a base word frequency effect. When pseudohomophones are read aloud after nonword controls, there was a pseudohomophone disadvantage but no base word frequency effect when delayed reading aloud is taken into account.

\section{Nonspecific Practice}

Responses in the delayed reading aloud task were approximately $32 \mathrm{msec}$ faster in the second block. This effect was not modulated by list order or the base word frequency of the pseudohomophone. Thus, it appears as though practice with the delayed reading aloud task did not differentially affect any of the manipulations in the present experiment and the effect is, therefore, best characterized as a nonspecific practice effect. We infer that this nonspecific practice effect does not account for the modulation of the pseudohomophone disadvantage and the base word frequency effect by list order.

It has been argued that if subjects are prepared to make a pronunciation in delayed reading aloud, this condition measures only factors that affect articulation itself (e.g., phoneme onset and ease of articulation). If subjects are not prepared to make a pronunciation, other factors that affect the retrieval of the motor program may also be measured (see Balota \& Chumbley, 1985, 1990; Monsell, Doyle, \& Haggard, 1989). In the present experiment, the online and delayed reading aloud conditions occurred on the same trial. Furthermore, the response-stimulus interval between online and delayed reading aloud was constant throughout the experiment. Therefore, it seems likely that the subjects were completely prepared to make the articulation in the delayed reading aloud condition. However, the fact that the base word frequency effect for pseudohomophones read aloud after nonword controls in online reading aloud is statistically the same size as that in delayed reading aloud is inconsistent with this interpretation. If the subjects were not completely prepared in delayed reading aloud, the base word frequency effect could arise during output processes as early as retrieving the motor program for articulation. Thus, some component of the base word frequency effect in the present experiment arises from output processes occurring later than lexical activation.

In summary, when pseudohomophones are read aloud in pure lists before nonword controls, there is a pseudohomophone disadvantage that co-occurs with a base word frequency effect. When pseudohomophones are read aloud in pure lists after nonword controls, the pseudohomophone disadvantage that co-occurs with a null base word frequency effect is reduced (but still present). 


\section{THE ACCOUNTS}

There are presently six empirical phenomena that need to be explained by any viable account of pseudohomophone reading aloud. In mixed list reading aloud, these are the conjunction of (1) a pseudohomophone advantage and (2) a null base word frequency effect. In pure list reading aloud, these are the conjunction of (3) a pseudohomophone disadvantage and (4) the presence of a base word frequency effect when pseudohomophones are read aloud before nonword controls, and the conjunction of (5) a reduced pseudohomophone disadvantage and (6) a reduced or null base word frequency effect when pseudohomophones are read aloud after nonword controls. We now will turn to six different accounts of pseudohomophone reading aloud and to a discussion of how well these accounts can explain these six findings.

\section{Theory 1: Frequency-Insensitive Lexical Activation (FILA)}

McCann and Besner (1987) have argued that nonwords are pronounced by the application of sublexical spelling-sound correspondences but that, in the case of a pseudohomophone, there is also activation of the base word's phonological (lexical) representation (see Figure 1). This provides an additional source of activation that affects phonemic-level processing and, hence, speeds up reading aloud. Nonword controls do not have such a base word representation; this advantage is, therefore, denied them. McCann and Besner's general account of the pseudohomophone advantage has been accepted by a number of researchers (Borowsky et al., 2002; Coltheart, Rastle, Perry, Langdon, \& Ziegler, 2001; Grainger et al., 2000; Marmurek \& Kwantes, 1996; Taft \& Russell, 1992).

Besner and colleagues (Baluch \& Besner, 1991; Besner, 1999; Besner \& Smith, 1992; Borowsky \& Besner, 1993; McCann \& Besner, 1987) also argued that there is no base word frequency effect in mixed lists because lexical representations are not frequency sensitive. Indeed, they have argued that the concurrent presence of a pseudohomophone advantage and the absence of a base word frequency effect poses a problem for all accounts that assume that lexical representations are frequency sensitive. Besner and colleagues suggested instead that word frequency may affect lexical-lexical connections (between orthographic and phonological lexicons) and lexical-semantic connections, rather than lexical representations per se.

Besner (1999) proposed that the presence of a base word frequency effect in a pure list could be explained by appealing to the idea that additional knowledge sources are involved, as compared with mixed list presentation. For example, subjects could recruit additional semantic knowledge when reading aloud the pseudohomophones. This produces a base word frequency effect, because lexical-semantic connections that are now in play are frequency sensitive.

Besner and colleagues' frequency-insensitive lexical activation account does not explicitly predict a pseudohomophone disadvantage. However, it can account for

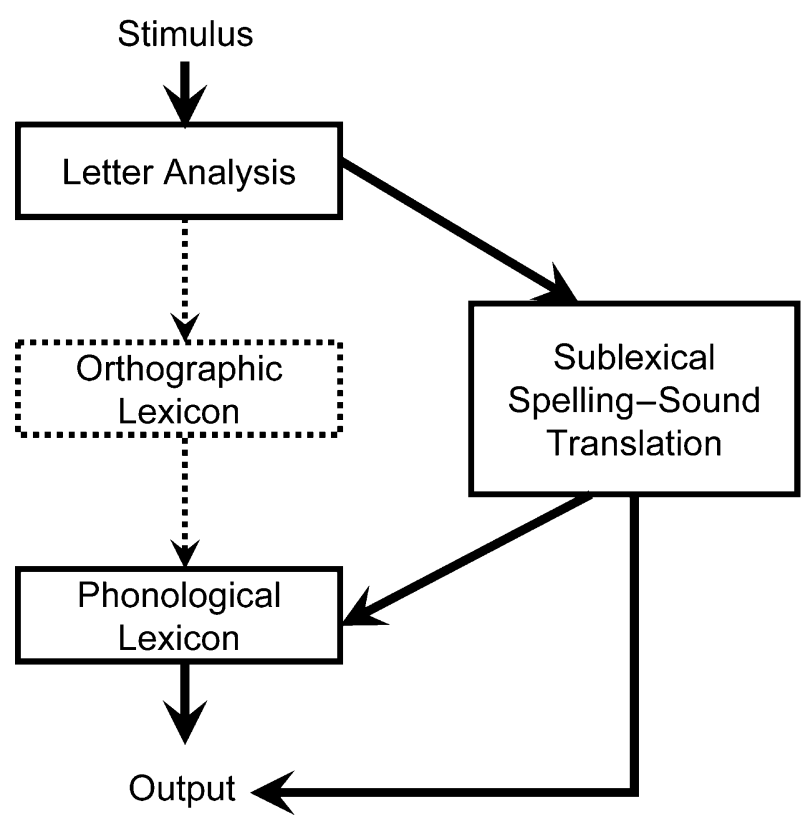

Figure 1. Besner and colleagues' frequency-insensitive lexical activation (FILA) account of pseudohomophone reading aloud.

this finding if the recruiting of semantics slows overall processing. Indeed, there is evidence that semantics can be involved in pseudohomophone reading aloud. Patterson, Suzuki, and Wydell (1996) reported the case of a Japanese patient (K.T.) suffering from phonological alexia (impaired nonword reading, but normal word reading). Although K.T. was very poor at reading nonwords aloud, he was much more accurate when reading pseudohomophones aloud. Patterson et al. also examined whether K.T.'s pseudohomophone reading performance was affected by imageability - a factor widely assumed to reflect the impact of semantic processing (e.g., Strain, Patterson, $\&$ Seidenberg, 1995). Critically, K.T. was more accurate at reading aloud pseudohomophones derived from highimageability words than pseudohomophones derived from low-imageability words.

Given that semantics plays a role, at least sometimes, in reading pseudohomophones aloud, it is possible that such contact produces the pseudohomophone disadvantage. However, in order for this to occur, the utilization of such knowledge would have to increase the overall time to read aloud a pseudohomophone despite the fact that factors that index semantics (e.g., imageability) produce a facilitatory effect. This is not as strange as it may sound at first. For example, contact with semantics could initially add noise to the system that increases the overall time to read aloud (pseudohomophone disadvantage), but this noise could be cleaned up more quickly for pseudohomophones derived from high-imageability base words than for pseudohomophones derived from low-imageability base words (a facilitatory effect of imageability). Thus, if contact with semantic knowledge has greater costs than benefits, this account can explain the modulation of 
the pseudohomophone disadvantage and the base word frequency effect by list order by appealing to the moderate application of these knowledge sources.

\section{Theory 2: Orthographic Overlap}

A quite different account of pseudohomophone reading aloud was proposed by Seidenberg and McClelland (1989), who examined whether their parallel distributed processing (PDP) model could simulate a pseudohomophone advantage, because in their model, "there does not seem to be a way for the spelling or pronunciation of BRAIN to directly influence BRANE because there is no lexical entry for BRAIN" (p. 555). Seidenberg and McClelland (1989) reported that their model produced a pseudohomophone advantage but that it was a consequence of more orthographic overlap with the base word than with the control items (as indexed by smaller orthographic error scores from the model). Seidenberg and McClelland (1989) therefore argued that the pseudohomophone advantage reported by McCann and Besner (1987) is not genuinely phonological.

Besner, Twilley, McCann, and Seergobin (1990) challenged Seidenberg and McClelland's (1989) account. They argued that if the orthographic overlap account is correct, controlling for this factor should eliminate the pseudohomophone advantage seen in skilled readers. Besner et al. therefore reanalyzed McCann and Besner's (1987) data by partialling out the orthographic error scores that are generated by running these items through Seidenberg and McClelland's (1989) model. Inconsistent with the purely orthographic overlap account, a pseudohomophone advantage persisted in McCann and Besner's data. (See Seidenberg \& McClelland [1989, pp. 555-556; 1990, pp. 449-450], Besner et al. [1990, pp. 441-443], and Besner [1999] for these exchanges.)

A related problem is that Seidenberg and McClelland (1989) did not discuss the null base word frequency effect reported by McCann and Besner (1987). It is not easy to tell whether their orthographic overlap account would produce a base word frequency effect or not. Although distributed models lack distinct lexical representations, if the orthographic pattern of a pseudohomophone is similar enough to its base word, it is possible for the pseudohomophone to systematically benefit from this. As Seidenberg and McClelland (1989) noted, cought would receive a greater benefit from orthographic overlap with caught than would the pseudohomophone cawt. If this is true, the absence of a base word frequency effect in the model could be a consequence of confounding base word frequency and orthographic overlap. The only way to find out whether this PDP model produces a base word frequency effect would be to run simulations in which these factors are not confounded. Seidenberg and McClelland (1989) did not report any simulations that address the effect of base word frequency.

A second problem for the orthographic overlap account is that it does not provide a mechanism whereby a pseudohomophone advantage and a null base word fre- quency effect seen in a mixed list could change to a pseudohomophone disadvantage and the presence of a base word frequency effect in a pure list. Nor does this account provide a mechanism by which list order can modulate these effects.

\section{Theory 3: Articulation}

Yet another account of the pseudohomophone advantage in reading aloud supposes that it arises entirely in articulation. Seidenberg et al. (1996) argued that pseudohomophones have "familiar, over-learned articulatory trajectories" (p. 53), whereas control nonwords have novel articulatory trajectories. According to this account, a pseudohomophone advantage is genuinely phonological (rather than orthographic, as in Seidenberg \& McClelland's, 1989, account) but arises later in processing.

Seidenberg et al. (1996) argued that if the pseudohomophone advantage arises entirely in articulation, it should be the same size in online and delayed reading aloud conditions. However, there are numerous delayed reading aloud methods, and the appropriateness of each method depends on what is being asked. For example, Balota and Chumbley $(1985,1990)$ advocated a delayed reading aloud condition in which subjects are not prepared to make the articulation, because some effects (e.g., word frequency) could arise, in part, through the retrieval of the motor program. In contrast, Monsell et al. (1989) advocated a delayed reading aloud procedure in which subjects are prepared to make the articulation, in order to assess whether effects occur during articulation itself. Seidenberg et al. (1996) used a delayed reading aloud procedure with two intervals for pronunciation: one that occurred two standard deviations after a subject's mean online RT and one that occurred four standard deviations after a subject's mean online RT. Given these deadlines, the subjects were likely prepared to make the articulation.

In accord with an articulation account, Seidenberg et al. (1996) reported an experiment with a 10-msec pseudohomophone advantage in the online reading aloud condition that persisted in the delayed reading aloud condition. The results from other experiments, however, are not consistent with a pure articulation account of the pseudohomophone advantage. For example, McCann and Besner (1987) included both online and delayed reading aloud conditions in their experiment. They reported a 36-msec pseudohomophone advantage in online reading aloud and a significantly smaller $11-\mathrm{msec}$ pseudohomophone advantage in delayed reading aloud. Taft and Russell (1992) reported a 30-msec pseudohomophone advantage in online reading aloud and a $10-\mathrm{msec}$ pseudohomophone advantage in delayed reading aloud (indeed, for fast subjects, they reported no pseudohomophone advantage at all). Furthermore, Besner (1999) reported a delayed reading aloud experiment, using Seidenberg et al.'s (1996) items and the procedure advocated by Monsell et al. (1989), in which the stimuli were read aloud twice in immediate succession. On the first $d e$ - 
layed reading aloud presentation, there was a 28-msec pseudohomophone advantage, but on the second delayed reading aloud presentation, this was reduced to $2 \mathrm{msec}$. This reduction in the size of the pseudohomophone advantage in the delayed reading aloud condition to essentially zero is inconsistent with a purely articulationbased account. With the exception of Seidenberg et al. (1996), then, none of these data are consistent with an account in which the only source of the pseudohomophone advantage is in articulation.

Another problem for Seidenberg et al.'s (1996) articulation account is that it predicts the conjunction of a pseudohomophone advantage and a base word frequency effect. If familiar articulatory trajectories are developed through repeated pronunciation, these trajectories should surely be affected by word frequency. As was noted previously, however, the conjunction of a pseudohomophone advantage and a base word frequency effect is not seen in experiments with skilled readers. Finally, it is difficult to envision how articulatory effects could switch directions in pure and mixed list reading aloud conditions or be modified by list order.

\section{Theory 4: Dual-Criterion Hypothesis}

Grainger et al. (2000) have proposed an account in which pseudohomophones can be read aloud using two criteria, whereas nonword controls are afforded only one. The default $A$ criterion is based on activation in articulatory units and can be used for both pseudohomophones and nonword controls. A second, $M$, criterion, based on activation in the phonological lexicon, acts as a fast-guess mechanism that facilitates pseudohomophone reading aloud time without affecting overall accuracy. To the extent that pseudohomophones are read aloud off the lexicon using the $\mathrm{M}$ criterion, there will be a pseudohomophone advantage. According to Grainger et al., if pseudohomophones are read using the $\mathrm{M}$ criterion a moderate amount, this will produce a pseudohomophone advantage and a null base word frequency effect, despite frequency-sensitive lexical processing. Grainger et al. also asserted that the base word frequency effect arises when pseudohomophones are read aloud in pure lists, because subjects use the $\mathrm{M}$ criterion more often. However, as the reader has likely anticipated, if reading off the lexicon facilitates pseudohomophone reading aloud, the dual-criterion account predicts a larger pseudohomophone advantage in the presence of a base word frequency effect, rather than the pseudohomophone disadvantage observed here and in Borowsky et al. (2002).

\section{Theory 5: Verification and Scaling}

Borowsky et al. (2002) have provided the most comprehensive account of pseudohomophone reading aloud. They proposed that subjects verify the phonological lexical status of the pseudohomophone in the pure block condition. The addition of this verification process increases the time it takes to read a pseudohomophone aloud, thus producing a pseudohomophone disadvantage. The veri- fication process utilizes frequency-sensitive processes (lexical representations or the links between lexical and semantic representations). According to Borowsky et al. (2002), increasing the time that frequency-sensitive processes are active increases the size of the base word frequency effect. In mixed list conditions, there is a "moderate probability of invoking a lexical retrieval strategy, without preventing mean latency from crossing over to produce a pseudohomophone disadvantage" (p. 984). The problem here (to us, at least) is that it is unclear to us how this would actually work. A more detailed description of the process and/or a simulation would be useful.

That said, Borowsky et al.'s (2002) account resembles lexical checking (for more discussion of this point, see Kinoshita \& Lupker, 2003; Lupker, Brown, \& Colombo, 1997; Reynolds \& Besner, 2005). The problem with lexical checking accounts is that they are usually post hoc and are typically underspecified (e.g., what happens if the verification process fails? Do subjects restart the reading process?). This makes these accounts difficult to assess.

Another problem with Borowsky et al.'s (2002) account is that it invokes a novel mechanism (verification) to explain the pseudohomophone disadvantage. In our view, it is premature to further complicate existing accounts. A better strategy is to assess whether existing accounts can be modified to explain the data. As we will demonstrate below, it is possible to explain all of these effects without invoking such a novel mechanism.

\section{Theory 6: The Dual Route Cascaded Model}

There is one other published account of pseudohomophone effects in reading aloud. This account is provided by Coltheart et al. (2001) and is nested in the context of their dual route cascaded (DRC) computational model of visual word recognition and reading aloud, which is considered to be "the most successful of current computational models of reading" (Coltheart et al., 2001, p. 204). As can be seen in Figure 2, the implemented version of the DRC model has two routes for translating print into sound.

The nonlexical route translates print into sound sublexically via a set of grapheme-phoneme correspondence rules applied left to right, one letter at a time. This route produces a correct pronunciation for words that follow typical spelling-to-sound rules (i.e., regular words) and is required to read nonwords (e.g., frane) aloud. The output from this route activates the phoneme system, where the activation of individual phonemes accumulates to some criterion. Reading aloud starts when all phonemes have reached criterion.

The lexical route consists of two lexicons. The orthographic lexicon contains a single node for each uniquely spelled word the model knows. The phonological lexicon contains a single node for each uniquely sounding word the model knows. Letter units activate words in the orthographic lexicon. Activation in the orthographic lexicon activates the letter units via feedback and the phono- 
logical lexicon via feedforward connections. Activation from the phonological lexicon feeds forward to the phoneme system and back to the orthographic lexicon. The lexical route can read aloud all the words it knows and is required to read aloud words that do not follow the typical spelling-to-sound rules (exception words such as pint). It cannot read nonwords correctly.

Coltheart et al. (2001) showed that the DRC model successfully simulates a pseudohomophone advantage. They argued that the pseudohomophone advantage produced by the DRC model arises through interactive activation between the phoneme system and the phonological lexicon. Consistent with this account, the pseudohomophone advantage is eliminated when the connections between the phonological lexicon and the phoneme system are lesioned by setting the connection weights to zero.

Coltheart et al.'s (2001) account differs from the account provided by McCann and Besner (1987; see also Besner, 1999; Besner \& Smith, 1992) in that lexical representations in the DRC model are frequency sensitive. Perhaps not surprisingly, the DRC model produces a base word frequency effect (see Coltheart et al., 2001, p. 225). This would appear to be a problem for the DRC model given that it produces the conjunction of a pseudohomophone advantage and a base word frequency effect,

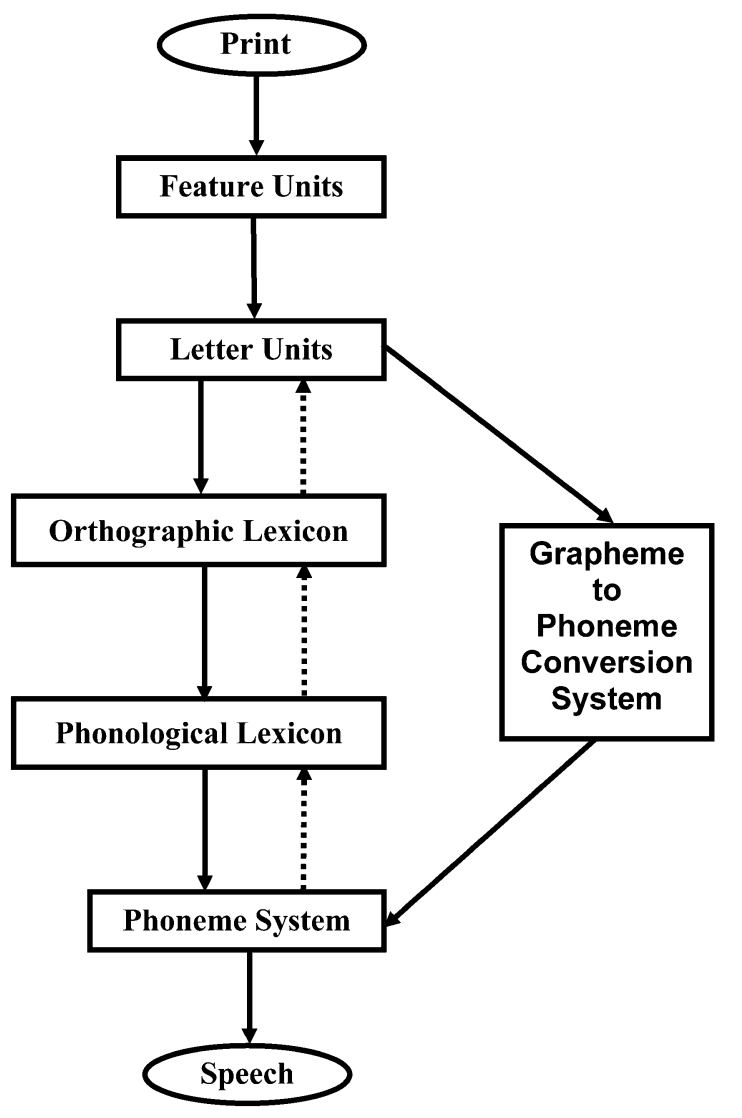

Figure 2. The dual route cascaded model's implemented architecture. whereas skilled readers do not produce this conjunction when pseudohomophones and nonwords are mixed together. However, this conclusion might be premature. Coltheart et al. used Taft and Russell's (1992) items in their simulation, but Herdman et al. (1996) have claimed that word frequency is confounded with orthographic factors in the Taft and Russell stimulus set. Thus, it is an empirical question as to whether the DRC model successfully simulates the conjunction of a pseudohomophone advantage and a null base word frequency effect if the stimulus list is properly controlled.

Testing the DRC model. The first step in assessing the DRC model is to create a stimulus set. Many of the stimuli used in studies of pseudohomophone reading aloud are not pseudohomophones in the DRC model, which uses Australian English. To avoid issues that may arise from using only a part of a stimulus set (e.g., approximately $50 \%$ of the items used by Borowsky et al. [2002] are not pseudohomphones in the DRC model), we created a larger stimulus list by combining the items used by Borowsky et al. (2002), Herdman et al. (1996, Experiment 2), and McCann and Besner (1987). These items can be seen in Appendix B.

The DRC model read 99\% of the pseudohomophones and $97 \%$ of the nonwords correctly. The correctly read aloud items produced a robust pseudohomophone advantage $[t(127)=11.3, S E M=1.2, p<.001]$. Two pseudohomophones (helled and bocks) were excluded from the analysis of base word frequency effects because they were over three standard deviations from the best-fitting line. As can be seen in Figure 3, the remaining items produced a robust base word frequency effect $[r=-.436$, $t(157)=6.1, p<.001] .^{3}$

The DRC model thus produces a pseudohomophone advantage and a base word frequency effect. Skilled readers do not produce this pattern. Thus, the DRC model does not successfully simulate the conjunction of a pseudohomophone advantage and the absence of a base word frequency effect seen in skilled readers when pseudohomophones and controls are mixed in the same list. Nor does the DRC model successfully simulate the conjunction of a pseudohomophone disadvantage and the presence of a base word frequency effect seen in skilled readers when pseudohomophones are read aloud before controls in pure lists. Nor does the DRC model successfully simulate the conjunction of a pseudohomophone disadvantage and the absence of a base word frequency effect observed when pseudohomophones are read aloud after nonword controls in pure lists.

\section{SUMMARY}

We have reviewed six different empirical phenomena and six different theoretical accounts. How the six different theoretical accounts fare is summarized in Table 3. Of the accounts discussed so far, only Borowsky et al.'s (2002) post hoc verification/scaling account can accommodate the pattern of effects seen in both pure and mixed list pseudohomophone reading aloud. As was noted ear- 


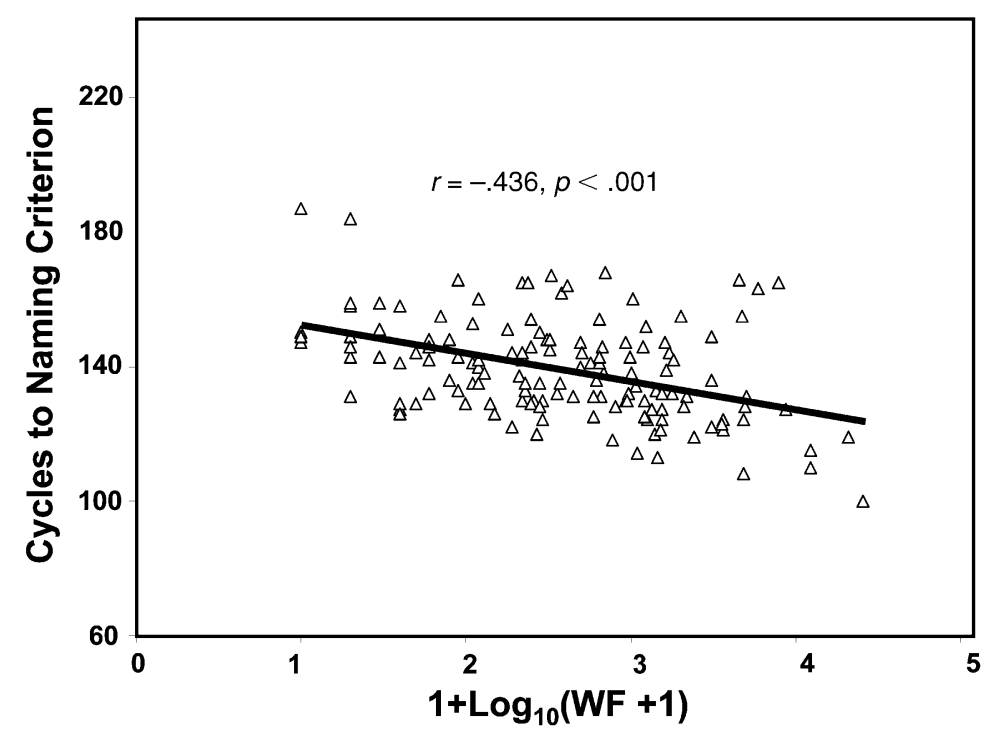

Figure 3. Cycles to reading aloud criterion in the dual route cascaded model (standard parameter set) for pseudohomophones as a function of base word frequency.

lier, this account is underspecified and invokes a novel mechanism to account for these data.

\section{A NEW ACCOUNT}

We now will propose a new account of pseudohomophone reading aloud that is able to account for all the pseudohomophone effects reviewed here. We then will implement this account in the DRC model, so as to provide an existence proof and to extend the range of effects that the DRC model can account for. In doing so, we also will demonstrate that it is possible to produce the conjunction of a pseudohomophone advantage and the absence of a base word frequency effect, despite the use of frequency-sensitive lexical representations. This is important because it undermines Besner and colleagues argument that the absence of a base word frequency effect in the presence of a pseudohomophone advantage is evidence that the lexical entries in the phonological lexicon are frequency insensitive. Finally, all these pseudohomophone effects can be produced without having to introduce a novel mechanism, such as the verification process that is central to Borowsky et al.'s (2002) account.

The basic premise of the account described here is that subjects can modulate how they use lexical knowledge. In pure list conditions, the base word dominates processing in the phonological output lexicon, whereas in mixed list conditions, many other lexical entries get ac-

Table 3

Success $(\checkmark)$ and Failure $(\times)$ at Producing the Six Pseudohomophone Reading Aloud Effects as a Function of Account Type

\begin{tabular}{|c|c|c|c|c|c|c|}
\hline \multirow[b]{3}{*}{ Account } & \multirow{2}{*}{\multicolumn{2}{|c|}{ Mixed List }} & \multicolumn{4}{|c|}{ Pure List } \\
\hline & & & \multicolumn{2}{|c|}{ PHs First } & \multicolumn{2}{|c|}{ PHs Second } \\
\hline & PH Advantage & $\begin{array}{c}\text { Absence } \\
\text { of a } \\
\text { BWFE }\end{array}$ & $\begin{array}{c}\text { PH } \\
\text { Disadvantage }\end{array}$ & $\begin{array}{c}\text { Presence } \\
\text { of a } \\
\text { BWFE }\end{array}$ & $\begin{array}{l}\text { Reduced PH } \\
\text { Disadvantage }\end{array}$ & $\begin{array}{c}\text { Absence } \\
\text { of a } \\
\text { BWFE }\end{array}$ \\
\hline 1. Besner and colleagues & & & & & & \\
\hline (Frequency-insensitive lexical activation) & $\checkmark$ & $\checkmark$ & $?$ & $\checkmark$ & ? & $?$ \\
\hline 2. Seidenberg \& McClelland (1989) & & & & & & \\
\hline (Orthographic overlap) & $\times$ & ? & $\times$ & $x$ & $\times$ & $\times$ \\
\hline 3. Seidenberg, Petersen, MacDonald, \& Plaut (1996) & & & & & & \\
\hline (Articulation) & $x$ & $\times$ & $x$ & $x$ & $x$ & $x$ \\
\hline 4. Grainger, Spinelli, \& Ferrand (2000) & & & & & & \\
\hline (Dual-criterion hypothesis) & $\checkmark$ & $\checkmark$ & $x$ & $\checkmark$ & $x$ & $x$ \\
\hline 5. Borowsky, Owen, \& Masson (2002) & & & & & & \\
\hline (Verification) & $\checkmark$ & $\checkmark$ & $\checkmark$ & $\checkmark$ & $\mathcal{J}$ & $\checkmark$ \\
\hline 6. Coltheart, Rastle, Perry, Langdon, \& Ziegler (2001) & & & & & & \\
\hline (Dual route cascaded) & $\checkmark$ & $x$ & $\times$ & $\checkmark$ & $x$ & $\times$ \\
\hline
\end{tabular}

Note-PH, pseudohomophone; BWFE; base word frequency effect. 
tivated as well. All of the six effects reviewed here fall out of this distinction.

This account makes the following assumptions about the reading of pseudohomophones and nonword controls: (1) Sublexical spelling-sound correspondences are used to generate a pronunciation for both pseudohomophones (e.g., brane) and nonword controls (e.g., frane); (2) general word knowledge (i.e., the activation of words that are similar in spelling and sound) facilitates the generation of a pronunciation for both pseudohomophones and nonword controls; (3) pseudohomophones and nonword controls differ in that pseudohomophones have an identical representation in the lexicon (brane $\rightarrow /$ brain/), so pseudohomophones receive a greater benefit than do nonword controls from their base word (a specific lexical representation); (4) the default for the reading aloud of nonwords is to use (mostly) general word knowledge, and the default for the reading aloud of pseudohomophones is to use (mostly) base word specific knowledge; (5) the emphasis on general word knowledge versus specific word knowledge can be modulated by list context; and (6) in order to isolate the contribution of a specific lexical representation, other lexical representations must be inhibited.

The default set for reading nonwords aloud is to use general word knowledge. The absence of an identical representation in the phonological lexicon discourages the use of a strategy that promotes the rise of activation in a single specific lexical entry. This is likely because, given a nonword, a single entry cannot be isolated (process failure) and/or the isolation of a single lexical entry that does not match the nonword may adversely affect performance (relative to no contact with any lexical entries). Although pseudohomophones can be read aloud with assistance from specific word knowledge corresponding to their base word, they can easily be read aloud using general word knowledge, when mixed with nonword controls.

\section{Mixed List Reading Aloud}

We will refer to nonword reading aloud that makes reference to word knowledge in general as the general activation strategy (GAS). For the sake of simplicity, it is assumed here that this strategy is always employed when (1) nonwords are read aloud and (2) pseudohomophones mixed with nonwords are read aloud. This strategy yields a pseudohomophone advantage, because pseudohomophones activate their base words more strongly than do nonword controls. Relative to nonword controls, the base word facilitates pseudohomophone reading aloud directly because it is a perfect phonological match to the pseudohomophone and indirectly by increasing the activation of other lexical representations that overlap orthographically and phonologically with the pseudohomophone. Pseudohomophones do not produce a base word frequency effect in this condition because, although their base word is active, its impact is diluted by other active lexical representations.

\section{Pure List Reading Aloud: Pseudohomophones First}

When pseudohomophones are read aloud in a pure list format before nonword controls, they reference their base word by using specific word knowledge, rather than general word knowledge. We refer to this as the specific activation strategy (SAS). Nonword controls, which are read aloud second, are still read via the GAS. According to this account, a pseudohomophone disadvantage occurs because very few representations are activated in the phonological lexicon for pseudohomophones. In contrast, there are many active lexical representations for the nonword controls. The greater the activation in the lexicon, the more facilitation a reading aloud response receives. Thus, although pseudohomophones are benefited by activation of their base words, this benefit is smaller than the one conveyed to nonword controls by multiple active lexical representations.

The pseudohomophones produce a base word frequency effect in a pure list because the base words dominate processing in the phonological lexicon via the use of the specific lexical activation strategy. The rise of activation for a base word is sensitive to frequency. Thus, there will be more activation for a high-frequency base word than for a low-frequency base word. The time to read aloud a pseudohomophone is sensitive to this rise in activation because it is not diluted by other active lexical representations.

\section{Pure List Reading Aloud: Pseudohomophones Second}

There are two possible ways that the present account can explain the reduced pseudohomophone disadvantage and reduced base word frequency effect seen when pseudohomophones are read aloud in a pure list format after nonword controls. One possibility is that subjects adopt either the SAS or the GAS strategy for reading the pseudohomophones aloud. That is, one could imagine that subjects have only two processing alternatives available to them. They can use either specific or general word knowledge, but not both. A second possibility is that a less extreme SAS strategy is used to read the pseudohomophones aloud. According to this account, pseudohomophones are read aloud by reference to their base words, but there are an intermediate number of activated entries in the lexicon. This residual activation facilitates pseudohomophone processing, so that they are read aloud more quickly than when they are read aloud first but more slowly than when lexical activation is not constrained, as in the GAS strategy. There is no base word frequency effect because the residual activation in the lexicon dilutes the contribution from frequency-sensitive processing of the base word.

Why would subjects utilize different types of lexical knowledge in different list contexts? Here, we postulate that subjects do not know how to assess their reading aloud accuracy for items they have never seen before. When reading nonwords aloud, for example, how can they assess whether their pronunciation is correct? If 
they were to compare the pronunciation they are generating with a specific lexical representation, this would have only limited value. It would not convey enough information about how the entire string of letters should be combined. As a result, they activate many lexical representations and, through converging evidence from lexical and sublexical processes, calculate the appropriate pronunciation. As they gain experience balancing these two sources of knowledge, they learn that this will allow them to generate a correct pronunciation.

When pseudohomophones are read, however, it becomes apparent to the subjects that one source of knowledge that they can use to assess their accuracy is the base word. By using a lexical activation strategy that encourages the rise of activation of the base word, subjects can safely generate a correct pronunciation through converging evidence from lexical and sublexical processes. When pseudohomophones are read aloud first, subjects likely do not learn that there is an alternative lexical activation strategy (GAS) that also can generate a correct pronunciation and is more effective. When pseudohomophones are read aloud after nonword controls, subjects likely learn that the base word can be used to generate the correct pronunciation, but they also have the GAS strategy available to them.

\section{SIMULATING GAS AND SAS}

Although the strategy account outlined here is arguably plausible, the devil is in the details. An existence proof by simulation would be more convincing. This is accomplished here in the context of Coltheart et al.'s (2001) DRC model. The parameter sets used to simulate mixed and pure list pseudohomophone reading aloud can be seen in Table 4. These parameter sets are constrained by two factors, in addition to their ability to simulate the six pseudohomophone effects. One is that the parameter sets must allow the DRC model to simulate all of the nonword effects it currently simulates. The second is that parsimony suggests there should be as few parameter changes as possible. (We emphasize that it is not being claimed that these are the only parameter values that will produce these effects. Rather, it is simply an existence proof.) To avoid confusion, it is important to note that we are not claiming that subjects read words aloud, using Coltheart et al.'s parameter set, and then switch to reading nonwords aloud, using the GAS parameter set. It is entirely possible that words are read aloud using either the GAS or the SAS parameter set, depending on context. However, this is beyond the scope of the present article. The purpose of the present simulation exercise is simply to demonstrate that the distinction between general and specific word knowledge can capture the pattern of results observed in pseudohomophone reading aloud.

In its simplest form, the critical difference between mixed list pseudohomophone reading aloud and pure list pseudohomophone reading aloud is whether a number of lexical representations are active or only a specific lexical representation is activated. In mixed list conditions, the GAS strategy is in play: The activation of general word knowledge is encouraged. In pure list conditions, the SAS strategy is in play, and the activation of base word specific knowledge is encouraged. Hence, we use a parameter set that encourages the activation of general word knowledge in the mixed list condition and a parameter set that encourages the activation of a particular lexical entry in the pure list condition.

There are three sets of parameters that directly affect the amount of lexical activation: (1) facilitatory connections into the lexicons, (2) inhibitory connections into the lexicons, and (3) lateral inhibition within the lexicons. The facilitatory connections into the lexicons from the letter units and the phoneme system activate lexical representations that contain the same letter or phoneme in the same position. The inhibitory connections into the lexicons from the letter units and the phoneme system inhibit representations that do not contain a particular letter or phoneme in the same position. Lateral inhibition within in the lexicons causes active lexical representations to inhibit the rise of activation of all other lexical representations.

To simplify the search through the DRC model's parameter space, we attempted to simulate pseudohomophone reading aloud by changing only one parameter. Coltheart et al. (2001) have reported a simulation with words in which they increased the number of active lexical representations by reducing inhibition into the orthographic lexicon and setting lateral inhibition in the lexicons to zero. We chose this as our starting point. Unfortunately, "the DRC model needs to have a high value for letter-to-word inhibition, such as .435, to prevent lexical capture of nonwords in reading aloud" (Coltheart et al., 2001, p. 225). This problem arises because, as Coltheart et al. noted "the most delicate issue with the DRC model is to try to set an appropriate balance between the two routes in the model" (p. 219). To avoid lexical capture in the present simulations the facilitatory connections from the phonological lexicon to the phoneme system were reduced for all of the simulations.

Figure 4 provides an example of how varying the strength of inhibitory connections into the orthographic lexicon affects lexical activation. As can be seen there, the GAS parameter set resulted in more and earlier activation in the phonological lexicon than did the SAS parameter set, both for the base word and for other lexical representations. This is consistent with the distinction drawn between specific and general lexical knowledge.

\section{Mixed List Reading Aloud}

As we have already noted, numerous studies have demonstrated that in mixed lists, pseudohomophones are (1) read aloud more quickly than their nonword controls and (2) do not produce a base word frequency effect. Our argument here is that pseudohomophones are read aloud in mixed lists by reference to general word knowledge (GAS). Therefore, both pseudohomophones and nonword controls are read aloud using the GAS. The stimulus set consisted of the items used above to test the DRC model's account of pseudohomophone reading aloud, 
Table 4

The Dual Route Cascaded Model's Default Parameter Values and the Parameter Values Used to Simulate the General Activation Strategy (GAS), Specific Activation Strategy (SAS), and Intermediate Activation Strategy (IAS)

\begin{tabular}{|c|c|c|c|c|}
\hline \multirow[b]{2}{*}{ Parameter } & \multirow[b]{2}{*}{$\begin{array}{c}\text { Default } \\
\text { Parameters }\end{array}$} & \multirow[b]{2}{*}{$\begin{array}{l}\text { Mixed List } \\
\quad(\mathrm{GAS})\end{array}$} & \multicolumn{2}{|c|}{ Pure List } \\
\hline & & & $\begin{array}{l}\text { PH First } \\
\text { (SAS) }\end{array}$ & $\begin{array}{l}\text { PH Second } \\
\text { (IAS) }\end{array}$ \\
\hline \multicolumn{5}{|l|}{ General } \\
\hline Activation rate & .20 & & & \\
\hline Frequency scale & .050 & & & \\
\hline Reading-aloud criterion & .43 & & & \\
\hline \multicolumn{5}{|l|}{ Feature level } \\
\hline Feature-to-letter excitation & .005 & & & \\
\hline Feature-to-letter inhibition & -.15 & & & \\
\hline Noise & & & & \\
\hline \multicolumn{5}{|l|}{ Letter level } \\
\hline Letter-to-orthographic excitation & .07 & & & \\
\hline Letter-to-orthographic inhibition & -.435 & -.250 & -.435 & -.385 \\
\hline Letter-to-letter inhibition & & & & \\
\hline Noise & & & & \\
\hline Decay & & & & \\
\hline \multicolumn{5}{|l|}{ Orthographic lexicon } \\
\hline Orthographic-to-phonological excitation & .20 & & & \\
\hline Orthographic-to-letter excitation & .30 & & & \\
\hline \multicolumn{5}{|l|}{ Orthographic-to-letter inhibition } \\
\hline Orthographic-to-orthographic inhibition & -.06 & 0 & 0 & 0 \\
\hline \multicolumn{5}{|l|}{ Noise } \\
\hline \multicolumn{5}{|l|}{ Decay } \\
\hline \multicolumn{5}{|l|}{ Phonological lexicon } \\
\hline Phonological-to-phoneme excitation & .14 & .014 & .014 & .014 \\
\hline Phonological-to-phoneme inhibition & 0 & & & \\
\hline Phonological-to-orthographic excitation & .20 & & & \\
\hline Phonological-to-phonological inhibition & -.07 & 0 & 0 & 0 \\
\hline Noise & & & & \\
\hline Decay & & & & \\
\hline \multicolumn{5}{|l|}{ Phoneme level } \\
\hline Phoneme-to-phonological excitation & .04 & & & \\
\hline Phoneme-to-phonological inhibition & -.16 & & & \\
\hline Phoneme-to-phoneme inhibition & -.15 & & & \\
\hline \multicolumn{5}{|l|}{ Noise } \\
\hline \multicolumn{5}{|l|}{ Decay } \\
\hline \multicolumn{5}{|l|}{ Grapheme-to-phoneme conversion (GPC) route } \\
\hline GPC-to-phoneme excitation & .055 & & & \\
\hline Cycles before new route begins & 10 & & & \\
\hline Cycles before next letter accessed & 17 & & & \\
\hline
\end{tabular}

along with the items from our experiment that are pseudohomophones in the DRC model (see Appendix C).

The pseudohomophone advantage. The $\mathrm{DRC}$ model correctly read aloud $96.2 \%$ of the pseudohomophones and $97.5 \%$ of the nonwords correctly. The pseudohomophones were read aloud nine cycles faster than the nonword controls $[t(194)=4.5$, SEM $=2.0, p<.05$; see Table 5].

The absence of a base word frequency effect. Two of the correctly read aloud pseudohomophones (plede and strete) were excluded from the regression analysis because they were over three standard deviations from the best-fitting line. The remaining pseudohomophones did not produce a base word frequency effect $[r=-.043$; $t(222)<1$; see Figure 5] (see note 3). It is clear that the DRC model is now successful in that it does not produce a pseudohomophone base word frequency effect when the general lexical activation parameter set is used. This finding is theoretically important because it demonstrates that it is possible to activate frequency-sensitive lexical representations but not have them produce a frequency effect, contrary to the interpretation advanced by Besner and colleagues (e.g., Baluch \& Besner, 1991; Besner, 1999; Besner \& Smith, 1992; Borowsky \& Besner, 1993; McCann \& Besner, 1987).

\section{Pure List Reading Aloud: When Pseudohomophones Are Named First}

As we have already noted, pseudohomophones read aloud in pure list presentation produce both a pseudohomophone disadvantage and a base word frequency effect when they are read aloud before nonword controls. According to the present account, when pseudohomo- 


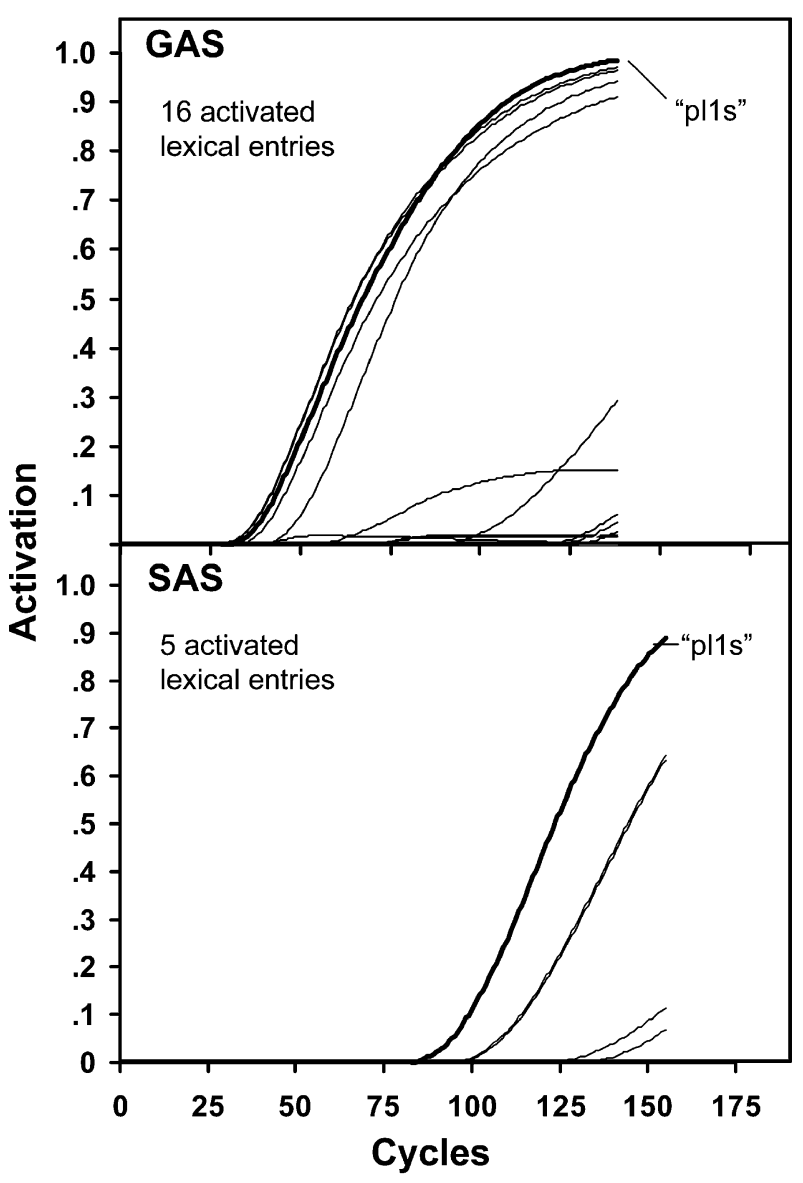

Figure 4. The rise of activation for entries in the phonological lexicon as a function of cycles to criterion for the general activation strategy (GAS) and the specific activation strategy (SAS) for the pseudohomophone plase.

phones are read aloud prior to nonword controls, subjects primarily activate only the base word in the lexicon. That is, pseudohomophones are primarily read aloud using the SAS (see Table 4).

The pseudohomophone disadvantage. Pseudohomophones read aloud using the SAS were compared with nonwords read aloud using the GAS (which is always used to read nonwords aloud). The DRC model made no pronunciation errors for the pseudohomophones. Critically, pseudohomophones took 17 cycles longer to read aloud than nonword controls $[t(200)=9.38, S E M=1.8$, $p<.01$; see Table 5].
The presence of a base word frequency effect. Three of the correctly read aloud pseudohomophones (helled, thryve, and strete) were excluded from regression analysis because they were over three standard deviations from the best-fitting line. The pseudohomophones produced a base word frequency effect $[r=-.16 ; t(230)=2.45$, $p<.05$; see Figure 5] that was significantly larger than the one reported in the simulation of mixed list reading aloud $[t(222)=16.0, S E M=0.85, p<.001] .{ }^{4}$ The DRC model is now successful in that it does produce a pseudohomophone base word frequency effect when the specific lexical activation parameter set is used, consistent with what is observed with skilled readers when pseudohomophones are read aloud before nonword controls.

\section{Pure List Reading Aloud: When \\ Pseudohomophones Are Read Aloud Second}

When pseudohomophones are read aloud in a pure list, but after nonword controls, they produce a reduced pseudohomophone disadvantage and a null base word frequency effect. Our suggestion here is that subjects use an intermediary strategy that has the properties of both SAS and GAS.

The pseudohomophone disadvantage. To simulate the reduced pseudohomophone disadvantage observed when pseudohomophones are read aloud second, we used a parameter set that sets inhibition to an intermediate value between the SAS and the GAS sets. We refer to this as the intermediate activation strategy (IAS). Pseudohomophones read aloud using the IAS were compared with the nonwords read aloud using the GAS (which is always used to read nonwords aloud). The model made no pronunciation errors for the pseudohomophones. The pseudohomophones took 3.7 cycles longer to read aloud than the nonword controls $[t(200)=2.1, S E M=1.8$, $p<.05$; see Table 5].

The absence of a base word frequency effect. The pseudohomophones were analyzed again to assess whether they produce a null base word frequency effect with this level of inhibition. Two of the pseudohomophones (helled and strete) were excluded from the regression analysis because they were over three standard deviations away from the best-fitting line. The pseudohomophones produced a null base word frequency effect $[r=-.108 ; t(231)=1.65$, $p>.10$; see Figure 5]. It should also be noted that this null base word frequency effect is significantly smaller than the base word frequency effect observed when the SAS parameter set is used $[t(230)=35.7, S E M=0.43, p<.001]$.

Table 5

Mean Number of Cycles to Reading Aloud Criterion in the Dual Route Cascaded Model for Pseudohomophones and Nonwords in Mixed and Pure List Conditions as a Function of Parameter Set

\begin{tabular}{lcccc}
\hline & & \multicolumn{3}{c}{ Pseudohomophones } \\
\cline { 3 - 4 } & Nonwords & Mixed List & Pure List First & Pure List Second \\
& GAS & GAS & IAS \\
\hline Cycles to reading aloud criterion & 132 & 123 & 149 & 136 \\
\hline Note-GAS, general activation strategy; SAS, specific activation strategy; IAS, intermediate activation strategy.
\end{tabular}




\section{PARAMETER SET}

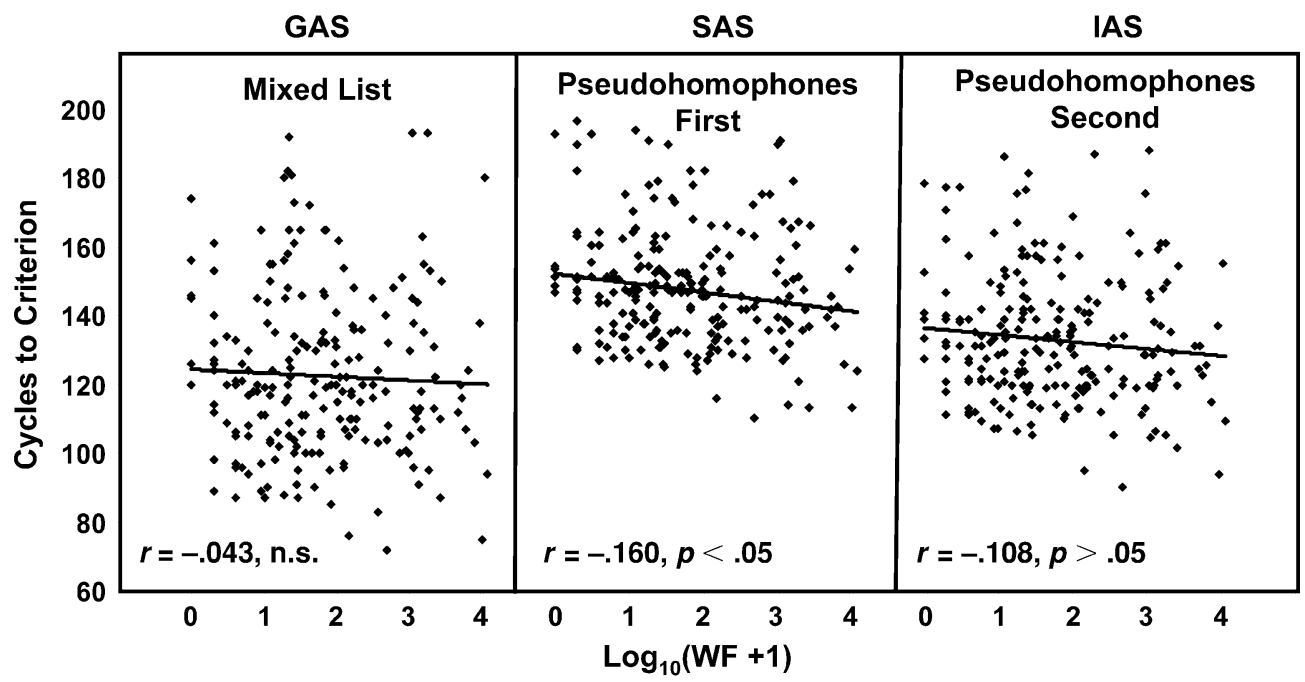

Figure 5. Cycles to reading aloud criterion in the dual route cascaded model for pseudohomophones as a function of base word frequency for the general activation strategy (GAS), specific activation strategy (SAS), and intermediate activation strategy (IAS) parameter sets.

\section{Summary}

The use of these three different parameter sets allows the DRC model to simulate the complex pattern of data observed in pseudohomophone reading aloud experiments. That is, the DRC model is now able to simulate (1) the conjunction of a pseudohomophone advantage and the absence of a base word frequency effect seen in mixed list reading aloud and (2) the conjunction of a pseudohomophone disadvantage and the presence of a base word frequency effect seen in pure list reading aloud when the pseudohomophones are read aloud first, and finally, (3) the conjunction of a pseudohomophone disadvantage and the absence of a base word frequency effect seen in pure lists when the pseudohomophones are read aloud after the nonword controls.

The lexical activation account described here differs from the verification account advocated by Borowsky et al. (2002). The verification account requires an additional lexical checking mechanism to account for the six effects reviewed here. In contrast, the lexical activation account appeals only to the inhibition of lexical representations to produce all of the pseudohomophone effects. In essence, the only difference between pseudohomophones read aloud in pure and mixed list conditions is the extent to which lexical representations are activated.

Reading nonwords aloud. If nonwords are always read aloud by using the GAS, it is essential that the DRC model be able to simulate known effects observed in nonword reading aloud by skilled readers when using this modified parameter set. Three critical effects in nonword reading aloud are (1) the letter length effect, (2) the whammy effect, and (3) the neighborhood density $(N)$ effect.

The letter length effect. The time it takes to read a nonword aloud increases with the number of letters (e.g.,
Weekes, 1997). This nonword length effect has been used by Coltheart et al. (2001) to justify the use of a serial sublexical spelling-to-sound translation process. Use of the GAS parameter set does not prevent the DRC model from producing a robust length effect for Weekes's items $[r=.438 ; t(96)=5.3, p<.001]$ when controlling for $N$ (see Table 6 and Appendix D).

The whammy effect. Rastle and Coltheart (1998) investigated how skilled readers' reading times to nonwords of a given length vary as a function of the number of phonemes. They found that it took longer to read aloud nonwords with fewer phonemes. This effect arises in the DRC model because the serial operation of the nonlexical route gives rise to spurious phoneme activation. For example, imagine that the grapheme th is submitted to the nonlexical route. Because each letter is entered serially, the DRC model will first generate the phoneme $t$; then when the $h$ is submitted, it will have to overcome the activation of the phoneme $t$ with the phoneme $T$. Rastle and Coltheart labeled this the whammy effect. To assess whether the GAS allows the DRC model to produce a whammy effect, the items from Rastle and Coltheart were run through the DRC model using the GAS parameter set (see Table 6 and Appendix E). These items produced a significant whammy effect $[t(21)=$ 2.6, SEM $=2.7, p<.05] .5$

The $N$ effect. A nonword's neighborhood is calculated by determining how many words differ from the item by only one letter and totaling them up. The more neighbors a nonword has, the more quickly it is read aloud (McCann \& Besner, 1987; Reynolds \& Besner, 2004). The ability of the GAS parameter set to produce an $N$ effect for nonwords is assessed here by running Reynolds and Besner's (2004) items through the model. The data can 
Table 6

Summary of the Nonword Reading Aloud Effects Simulated

Using the GAS Parameter Set

\begin{tabular}{lcc}
\hline Nonword Length & Length & \\
Weekes (1997) stimulus set & $r=.438$ & \\
Whammies & Whammied & Nonwhammied \\
Rastle \& Coltheart (1998) stimulus set & 152 & 145 \\
Neighborhood Density & High $N$ & Low $N$ \\
Reynolds \& Besner (2004) stimulus set & 85 & 115 \\
\hline Note-Latencies are in cycles to criterion. & &
\end{tabular}

Note-Latencies are in cycles to criterion.

be seen in Table 4, and the DRC model's latencies can be seen in Appendix F. The DRC model produces a significant $N$ effect $[t(39)=16.6, S E M=1.8$, p. $<.001]$.

\section{GENERAL DISCUSSION}

We have reviewed six effects from the pseudohomophone reading aloud literature and six accounts of these effects. We have illustrated how four of these accounts could not explain many of these effects and have identified a number of problems for the remaining accounts. A new account was proposed to explain all six of the observed effects. The central premise of this account is that subjects use lexical knowledge differently depending on the list context. When pseudohomophones and nonword controls are read aloud in a mixed list, they are read using general word knowledge (e.g., lexical representations that are orthographically and phonologically similar to the target). Pseudohomophones read aloud in a mixed list are processed using general word knowledge, because nonword controls lack a specific lexical representation. This is referred to as the general activation strategy (GAS). When pseudohomophones are read aloud prior to nonword controls in a pure list, they mainly activate their base words in the phonological lexicon, using the specific activation strategy (SAS). This strategy was simulated here by inhibiting the activation of lexical representations. Pseudohomophones read aloud after nonword controls in the pure list condition are read using an intermediate point on this continuum (as indexed by the IAS parameter set). This lexical activation strategy account was implemented in Coltheart and colleagues' DRC model and successfully produced all six effects. In addition, the GAS parameter set used for nonword reading aloud simulated three critical findings from the nonword reading aloud literature - that is, (1) as letter length increases, so does the time to read aloud; (2) whammies increase the time to read aloud; and (3) as the number of neighbors increases, the time to read aloud decreases.

\section{Locus of the Word Frequency Effect}

The present simulation exercise is also theoretically important because it demonstrates that frequency-sensitive representations need not give rise to a frequency effect. This undermines Besner and colleagues' (Baluch \& Besner, 1991; Besner, 1999; Besner \& Smith, 1992; Borowsky \& Besner, 1993; McCann \& Besner, 1987) inference that the joint finding of a pseudohomophone advantage and the absence of a base word frequency effect in reading aloud is inconsistent with lexical representations in the phonological lexicon being frequency sensitive. Relatedly, the present simulation exercise shows that it is possible to account for a range of effects without appealing to the operation of an (opaque) verification process (which in any case, does not play a role in the reading of words aloud).

\section{Context Effects}

There are numerous accounts of visual word recognition, where it has been argued that skilled readers can modulate the dynamics of the reading system (Monsell, Patterson, Graham, Hughes, \& Milroy, 1992; Reynolds \& Besner, 2005; Zevin \& Balota, 2000). However, these accounts have been concerned with how different routes for translating print into sound can be modulated (e.g., Baluch \& Besner, 1991; Zevin \& Balota, 2000) or how various levels of representation do or do not interact in different contexts (e.g., Brown \& Besner, 2002; Smith \& Besner, 2001; Stolz \& Neely, 1995). The present work emphasizes a third alternative-namely, the type of information extracted from the lexicon: specific word knowledge from the activation of a particular lexical representation versus general word knowledge from the activation of many lexical representations.

\section{Future Directions}

Two issues that come easily to mind merit further investigation. One concerns the respective roles that orthographic neighbors (Grainger et al., 2000; McCann \& Besner, 1987; Reynolds \& Besner, 2004) and phonological neighbors (Mulatti, Besner, \& Job, 2003; Reynolds, Mulatti, \& Besner, 2004) play in pseudohomophone reading aloud. The point here is that orthographic and phonological neighbors are typically confounded. More analytic experiments are required to assess what respective roles they play in pseudohomophone (and nonword and word) reading aloud.

A second issue concerns the role that semantics may play in pseudohomophone reading aloud. Proponents of the PDP approach sometimes argue that pseudohomophone effects arise through the action of the semantic system. One way to investigate this is to examine whether there are pseudohomophone effects in reading aloud for patients with no ability to access semantics from print. For example, Bub, Cancelliere, and Kertesz (1985) re- 
port the case of M.P., who has an acute loss of language comprehension but uses lexical knowledge to read words and is also able to read nonwords. A demonstration that contact with semantics is not necessary to produce various pseudohomophone effects in reading aloud in such patients would presumably raise problems for the PDP account. Relatedly, one could jointly manipulate imageability and pseudohomophony in experiments with intact skilled readers. A failure to see an effect of imageability on the time to read aloud pseudohomophones would raise problems for the view that semantics standardly plays a role here 6 and would leave PDP models with the ongoing problem of how to produce these various pseudohomophone effects in intact readers.

\section{Conclusion}

The lexical activation strategy account provided here is currently the only implemented computational account that correctly simulates all six of the effects reported here. We reiterate a conclusion reached elsewhere (Reynolds \& Besner, 2005): Processing in reading aloud appears to be considerably more dynamic than is generally acknowledged.

\section{REFERENCES}

Balota, D., \& Chumbley, J. I. (1985). The locus of word-frequency effects in the pronunciation task: Lexical access and/or production? Journal of Memory \& Language, 24, 89-106.

Balota, D., \& Chumbley, J. I. (1990). Where are the effects of frequency in visual word recognition tasks? Right where we said they were! Comment on Monsell, Doyle, and Haggard (1989). Journal of Experimental Psychology: General, 119, 231-237.

BALUCH, B., \& BESNER, D. (1991). Visual word recognition: Evidence for strategic control of lexical and nonlexical routines in oral reading. Journal of Experimental Psychology: Learning, Memory, \& Cognition, 17, 644-652.

BESNER, D. (1999). Basic processes in reading: Multiple routines in localist and connectionist models. In R. M. Klein \& P. A. McMullen (Eds.), Converging methods for understanding reading and dyslexia (pp. 413-458). Cambridge, MA: MIT Press.

Besner, D., \& SMith, M. (1992). Basic processes in reading: Is the orthographic depth hypothesis sinking? In R. Frost \& L. Katz (Eds.), Orthography, phonology, morphology, and meaning (pp. 45-66). Amsterdam: Elsevier, North-Holland.

Besner, D., Twilley, L., McCann, R. S., \& Seergobin, K. (1990). On the association between connectionism and data: Are a few words necessary? Psychological Review, 97, 432-446.

BorowsKy, R., \& BESNER, D. (1993). Visual word recognition: A multistage activation model. Journal of Experimental Psychology: Learning, Memory, \& Cognition, 19, 813-840.

Borowsky, R., Owen, W. J., \& Masson, M. E. J. (2002). Diagnostics of phonological lexical processing: Pseudohomophone naming advantages, disadvantages, and base-word frequency effects. Memory \& Cognition, 30, 969-987.

Borowsky, R., Phillips, J., \& OWen, W. (2003, June). Phonetic decoding processes: On the generalization of the dissociation of frequency and lexicality effects in pseudohomophone naming. Paper presented at the 13th Annual Meeting of the Canadian Society for Brain Behaviour and Cognitive Science, Hamilton, ON.

Brown, M., \& Besner, D. (2002). Semantic priming: On the role of awareness in visual word recognition in the absence of an expectancy. Consciousness \& Cognition, 11, 402-422.

Bub, D., Cancelliere, A., \& Kertesz, A. (1985). Whole-word and analytic translation of spelling to sound in a non-semantic reader. In
K. E. Patterson, J. C. Marshall, \& M. Coltheart (Eds.), Surface dyslexia: Neuropsychological and cognitive studies of phonological reading (pp. 15-34). London: Erlbaum.

Coltheart, M., Rastle, K., Perry, C., Langdon, R., \& Ziegler, J. (2001). DRC: A dual route cascaded model of visual word recognition and reading aloud. Psychological Review, 108, 204-256.

Forster, K. I., \& Chambers, S. M. (1973). Lexical access and naming time. Journal of Verbal Learning \& Verbal Behavior, 12, 627-635.

GraingER, J., SPINELLI, E., \& FERRAND, L. (2000). Effects of base word frequency and orthographic neighborhood size in pseudohomophone naming. Journal of Memory \& Language, 42, 88-102.

Herdman, C. M., LeFevre, J.-A., \& Greenham, S. L. (1994). Implicating the lexicon: Base-word frequency effects in pseudohomophone naming. Journal of Experimental Psychology: Human Perception \& Performance, 20, 575-590.

Herdman, C. M., LeFevre, J.-A., \& Greenham, S. L. (1996). Baseword frequency and pseudohomophone naming. Quarterly Journal of Experimental Psychology, 49A, 1044-1061.

HoAglin, D. C., \& WeLsCH, R. E. (1978). The hat matrix in regression and ANOVA. American Statistician, 32, 17-22.

Kinoshita, S., \& LUPKER, S. J. (2003). Priming and attentional control of lexical and sublexical pathways in naming: A re-evaluation. Journal of Experimental Psychology: Learning, Memory, \& Cognition, 29, 405-415.

LuPKER, S. J., BRown, P., \& ColOMBo, L. (1997). Strategic control in a naming task: Changing routes or changing deadlines? Journal of Experimental Psychology: Learning, Memory, \& Cognition, 23, 570-590.

MARMureK, H. H. C., \& Kwantes, P. J. (1996). Reading words and wirds: Phonology and lexical access. Quarterly Journal of Experimental Psychology, 49A, 696-714.

MCCANN, R. S., \& BESNER, D. (1987). Reading pseudohomophones: Implications for models of pronunciation assembly and the locus of word frequency effects in naming. Journal of Experimental Psychology: Human Perception \& Performance, 13, 14-24.

Monsell, S., Doyle, M. C., \& Haggard, P. N. (1989). Effects of frequency on visual word recognition tasks: Where are they? Journal of Experimental Psychology: General, 118, 43-71.

Monsell, S., Patterson, K. E., Graham, A., Hughes, C. H., \& MilROY, R. (1992). Lexical and sublexical translation of spelling to sound: Strategic anticipation of lexical status. Journal of Experimental Psychology: Learning, Memory, \& Cognition, 18, 452-467.

MulatTi, C., BeSNER, D., \& Job, R. (2003, November). Reading aloud: Evidence for a phonologically based neighborhood density effect. Poster presented at the 44th Annual Meeting of the Psychonomic Society, Vancouver.

PAtterson, K., Suzuki, T., \& Wydell, T. N. (1996). Interpreting a case of Japanese phonological alexia: The key is in phonology. $\underline{\operatorname{Cog}}$ nitive Neuropsychology, 13, 803-822.

RASTLE, K., \& COLTHEART, M. (1998). Whammies and double whammies: The effect of length on nonword reading. Psychonomic Bulletin \& Review, 5, 277-282.

REYNOLDS, M., \& BESNER, D. (2004). Neighbourhood density, word frequency, and spelling-sound regularity effects in naming: Similarities and differences between skilled readers and the dual route cascaded computational model. Canadian Journal of Experimental Psychology, 58, 13-31.

REYNOLDS, M., \& BESNER, D. (2005). Contextual control of lexical and sublexical routines when reading English aloud. Psychonomic Bulletin \& Review, 12, 113-118.

ReYnolds, M., Mulatti, C., \& Besner, D. (2004, June). Spying on your neighbors: Orthographic and phonological effects in naming. Poster presented at the 14th Annual Meeting of the Canadian Society for Brain, Behaviour and Cognitive Science, St. Johns, NF.

Roberts, M. A., Rastle, K., Coltheart, M., \& Besner, D. (2003). When parallel processing in visual word recognition is not enough: New evidence from naming. Psychonomic Bulletin \& Review, 10, 405-414.

SEIDENBERG, M. S., \& McClelland, J. L. (1989). A distributed, developmental model of word recognition and naming. Psychological Review, 96, 523-568. 
Seidenberg, M. S., \& McClelland, J. L. (1990). More words but still no lexicon: Reply to Besner et al. (1990). Psychological Review, 97, 447-452.

Seidenberg, M. S., Petersen, A., MacDonald, M. C., \& Plaut, D. C. (1996). Pseudohomophone effects and models of word recognition. Journal of Experimental Psychology: Learning, Memory, \& Cognition, 22, 48-62.

SMITH, M. C., \& Besner, D. (2001). Modulating semantic feedback in visual word recognition. Psychonomic Bulletin \& Review, 8, 111-117.

Stolz, J. A., \& NeEly, J. H. (1995). When target degradation does and does not enhance semantic context effects in word recognition. Journal of Experimental Psychology: Learning, Memory, \& Cognition, 21, 596-611.

Strain, E., Patterson, K. E., \& Seidenberg, M. S. (1995). Semantic effects in single word naming. Journal of Experimental Psychology: Learning, Memory, \& Cognition, 21, 1140-1154.

TAFT, M., \& Russell, B. (1992). Pseudohomophone naming and the word frequency effect. Quarterly Journal of Experimental Psychology, 45A, 51-71.

VAN SELST, M., \& Jolicceur, P. (1994). A solution to the effect of sample size on outlier elimination. Quarterly Journal of Experimental Psychology, 47A, 631-650.

WEEKES, B. (1997). Differential effects of letter number of word and nonword naming latency. Quarterly Journal of Experimental Psychology, 50A, 439-456.

ZeVIN, J. D., \& BALOTA, D. A. (2000). Priming and attentional control of lexical and sublexical pathways during naming. Journal of Experimental Psychology: Learning, Memory, \& Cognition, 26, 121-135.

\section{NOTES}

1. Herdman, LeFevre, and Greenham (1994) have reported a reversed base word frequency effect for pseudohomophones read aloud among nonwords and words, using a subset of McCann and Besner's (1987) stimulus set. Interpretation of their data is complicated by their use of only 20 of the original 80 pseudohomophones per subject for their analysis of a base word frequency effect. Although Herdman et al. (1994) reported data from a delayed reading aloud condition, it was collected from a different set of subjects. Furthermore, more errors were made in delayed reading aloud than in online reading aloud. Some data suit no theory.

2. The data were also analyzed excluding items that subjects did not recognize as sounding like words they knew. The pattern of results did not change.

3.The differences in degrees of freedom associated with lexicality and base word frequency effects are due to Herdman et al.'s (1996) items being matched in triplets. High- and low-frequency pseudohomophones are collapsed into a single score for the purposes of comparing pseudohomophones and nonword controls. Changes in the degrees of freedom for analyses across parameter sets are due to errors.

4. There is very little error variability in the item latencies between the different simulations.

5. The nonwhammy item fruls and its control fooce were excluded from the analyses because the former has a whammy in the final position $(/ \mathrm{s} / \rightarrow / \mathrm{z} /)$.

6. To date, we have failed to observe an imageability effect in pseudohomophone reading aloud by university-level readers.

APPENDIX A

Pseudohomophones and Nonword Controls Used in the Experiment

\begin{tabular}{|c|c|c|c|c|c|c|c|}
\hline \multicolumn{4}{|c|}{ Pseudohomophones } & & & & \\
\hline Low $\mathrm{I}$ & uency & High & uency & \multicolumn{4}{|c|}{ Nonword Controls } \\
\hline bok & glene & bol & gud & baif & glae & binc & kud \\
\hline bain & groap & berd & groop & baps & grok & blait & makt \\
\hline basc & hoan & blak & hoap & bazed & haiv & boap & nol \\
\hline blote & mame & bote & mete & blawnt & mawg & boart & phek \\
\hline busc & noap & boath & noze & bont & nasc & bost & phlur \\
\hline kalk & paiv & kamp & paje & kern & pene & chak & phunt \\
\hline kelt & fazed & kase & fone & koez & fet & chilm & plawg \\
\hline chaif & plede & chare & plase & chote & plinc & chite & poan \\
\hline chyde & pron & chek & pryce & chawd & prich & cish & prud \\
\hline chern & seap & cherch & saif & chail & $\mathrm{sab}$ & derd & serk \\
\hline klaps & soke & kost & sed & klain & sair & drase & sheem \\
\hline clawd & skab & coart & skeme & cloom & skoze & famp & shoath \\
\hline dise & shean & dawg & shud & dont & shoap & fane & shyce \\
\hline dawnt & shail & drinc & shoan & doan & shede & fett & skaje \\
\hline finc & snair & fakt & smol & fusc & snue & flerch & smiew \\
\hline fers & stich & feer & stait & fise & staip & fote & sone \\
\hline flont & strue & fiew & strete & flers & stralk & frete & stete \\
\hline flae & shoarn & philm & shur & flon & shype & gare & stred \\
\hline flawg & tont & phish & teem & floke & teap & gat & tase \\
\hline floom & thryve & phlat & thrett & floap & thryde & grol & thraif \\
\hline foze & trype & flite & trane & foarn & trean & haim & troze \\
\hline $\begin{array}{l}\text { phret } \\
\text { gaip }\end{array}$ & woez & $\begin{array}{l}\text { frunt } \\
\text { gaim }\end{array}$ & werk & $\begin{array}{l}\text { phryve } \\
\text { gelt }\end{array}$ & wame & $\begin{array}{l}\text { keer } \\
\text { koop }\end{array}$ & weme \\
\hline
\end{tabular}


APPENDIX B

Cycles to Reading Aloud Criterion for the Pseudohomophones and Nonword Controls Used to Assess Whether the DRC Model Produces the Conjunction of a Pseudohomophone Advantage and a Base Word Frequency Effect

\begin{tabular}{|c|c|c|c|c|c|c|c|c|c|c|c|c|c|}
\hline \multicolumn{8}{|c|}{ Pseudohomophones } & \multicolumn{6}{|c|}{ Nonword Controls } \\
\hline furst & 115 & surve & 138 & hoald & 147 & gaim & 132 & gurst & 149 & furve & 154 & hoalt & 156 \\
\hline hazz & 119 & roal & 130 & breaz & 140 & gole & 148 & nazz & 142 & zoal & 138 & brean & 147 \\
\hline yung & 166 & nues & 146 & braiv & 137 & hed & 108 & nung & 190 & fues & 149 & brair & 176 \\
\hline keap & 123 & wirth & 138 & boan & 130 & heet & 125 & feap & 137 & hirth & 159 & boam & 137 \\
\hline wunce & 163 & gane & 147 & bern & 135 & hoam & 131 & tunce & 181 & hane & - & berv & 143 \\
\hline wawl & 120 & groe & 132 & theem & 150 & keap & 123 & vawl & 143 & broe & 152 & theen & 155 \\
\hline rong & 155 & waije & 146 & phlash & 165 & reech & 143 & mong & 158 & faije & 156 & phlast & 171 \\
\hline grean & 127 & slite & 162 & swoar & 166 & weel & 124 & drean & 143 & klite & 202 & swoam & 156 \\
\hline ferm & 118 & durt & 130 & coalt & 141 & tair & 144 & serm & 137 & jurt & 136 & coaft & 147 \\
\hline reech & 143 & coad & 130 & stroal & 148 & flud & 126 & meech & 165 & doad & 134 & stroat & 170 \\
\hline dait & 131 & fome & 136 & soke & 143 & focks & 135 & yait & 138 & yome & 138 & sofe & 146 \\
\hline ment & 113 & taip & 133 & seaks & 142 & stane & 155 & nent & 119 & baip & 139 & seafs & 148 \\
\hline choyce & 160 & keeze & 151 & burth & 136 & mair & 144 & phoyce & 200 & veeze & 156 & lurth & 168 \\
\hline bote & 141 & berd & 131 & fayst & 144 & pait & 129 & wote & 172 & perd & 130 & nayst & 156 \\
\hline dreem & 131 & sope & 142 & fownd & 128 & fleigh & 187 & breem & 143 & zope & 156 & nownd & 156 \\
\hline gess & 125 & nerse & 135 & groope & 149 & laice & 160 & dess & 127 & merse & 154 & moope & 156 \\
\hline pruve & 154 & bern & 135 & leest & 121 & daim & 136 & bruve & - & pern & 131 & deest & 156 \\
\hline raize & 140 & $\operatorname{trax}$ & 122 & looz & 128 & fole & 149 & kaize & 155 & prax & 141 & gooz & 133 \\
\hline shooze & 168 & leese & 144 & maik & 127 & sted & 126 & frooze & 163 & heese & 155 & daik & 135 \\
\hline thret & 131 & glew & 141 & milc & 114 & bleet & 146 & shret & 153 & plew & 149 & filc & 131 \\
\hline prufe & 167 & burth & 136 & proov & 141 & doam & 135 & trufe & 194 & turth & 169 & troov & 155 \\
\hline golph & 148 & derth & 143 & shaip & 146 & weap & 133 & & 169 & kerth & 167 & traip & 143 \\
\hline boan & 130 & binje & 184 & tirn & 119 & peech & 158 & poan & 137 & jinje & 184 & nirn & 143 \\
\hline waik & 132 & turse & 146 & trayd & 139 & neel & 129 & haik & 135 & burse & 151 & crayd & 156 \\
\hline mait & 129 & wead & 129 & waije & 146 & & & pait & 129 & gead & 132 & laije & 156 \\
\hline supe & 165 & hoest & 143 & gurth & 159 & & & zupe & 177 & hoert & 156 & sair & 150 \\
\hline phocks & 153 & stait & 136 & layst & 146 & & & snocks & 163 & shait & 154 & brud & 142 \\
\hline pirl & 132 & doun & 110 & hownd & 143 & & & birl & 133 & loun & 139 & vocks & 140 \\
\hline coph & 141 & owt & 100 & soope & 144 & & & goph & 153 & ost & 121 & prane & 175 \\
\hline perge & 159 & helled & ${ }^{*} 195$ & feest & 138 & & & berge & 165 & helked & 207 & gair & 146 \\
\hline cheet & 148 & leest & 121 & booz & 127 & & & preet & 156 & leext & 156 & nait & 138 \\
\hline lirch & 158 & gaim & 132 & caik & 135 & & & wirch & 162 & gair & 146 & teigh & 176 \\
\hline fole & 149 & wyfe & 131 & silc & 120 & & & vole & 83 & vyfe & 177 & gaice & 169 \\
\hline gool & 131 & fyne & 133 & groov & 142 & & & bool & 131 & fyce & - & raim & 135 \\
\hline pirck & 150 & wawk & 124 & draip & 147 & & & virck & 156 & wawf & 137 & jole & 154 \\
\hline hokes & 151 & bote & 141 & birn & 128 & & & lokes & 170 & boke & 167 & gled & 133 \\
\hline yeer & 124 & layt & 128 & spayd & 149 & & & keer & 155 & payt & 129 & breet & 154 \\
\hline groop & 122 & gyde & 164 & raije & 145 & & & & 146 & gyfe & 177 & goam & 138 \\
\hline fownd & 128 & feeld & 127 & bair & 143 & & & yownd & 156 & teeld & 156 & meap & 131 \\
\hline leest & 121 & flore & 144 & blud & 121 & & & heest & 156 & flove & 197 & feech & 165 \\
\hline feal & 124 & woak & 129 & bocks & $* 77$ & & & beal & 134 & woaf & 142 & beel & - \\
\hline hoap & 132 & hoap & 132 & brane & - & & & goap & 138 & hoaj & 143 & & \\
\hline peece & 130 & boarn & 147 & cair & 142 & & & deece & 169 & boarm & 149 & & \\
\hline blud & 121 & nyse & 152 & dait & 131 & & & clud & 131 & nyre & 177 & & \\
\hline cheef & 134 & cleen & 130 & deigh & 165 & & & bleef & 156 & cleem & 156 & & \\
\hline dowt & 124 & foart & 154 & faice & 155 & & & kowt & 143 & loart & 162 & & \\
\hline
\end{tabular}

Note-There are unequal numbers of pseudohomophones and nonwords because Herdman et al. (1996) used twice as many pseudohomophones as nonword controls. Dashes indicate items read incorrectly by the DRC model. * Items excluded from the base word frequency analysis. 
APPENDIX C

Cycles to Reading Aloud Criterion for Pseudohomophones (PHs) and Nonword Controls With the GAS, the SAS, and the IAS Parameter Sets

\begin{tabular}{|c|c|c|c|c|c|c|c|c|c|c|c|}
\hline \multicolumn{4}{|c|}{ Pseudohomophones } & \multirow{2}{*}{\multicolumn{2}{|c|}{$\underline{\text { Nonword Controls }}$}} & \multicolumn{4}{|c|}{ Pseudohomophones } & \multirow{2}{*}{\multicolumn{2}{|c|}{ Nonword Controls }} \\
\hline \multirow[b]{2}{*}{ Item } & \multirow{2}{*}{$\begin{array}{c}\text { Mixed } \\
\text { GAS }\end{array}$} & \multirow{2}{*}{$\begin{array}{l}\text { PH 2nd } \\
\text { IAS }\end{array}$} & \multirow{2}{*}{$\begin{array}{l}\text { PH 1st } \\
\text { SAS }\end{array}$} & & & \multirow[b]{2}{*}{ Item } & \multirow{2}{*}{$\begin{array}{l}\text { Mixed } \\
\text { GAS }\end{array}$} & PH 2nd & PH 1st & & \\
\hline & & & & Item & GAS & & & IAS & SAS & Item & GAS \\
\hline furst & 110 & 131 & 140 & gurst & 114 & roal & 96 & 115 & 132 & zoal & 105 \\
\hline yung & 118 & 153 & 174 & nung & 131 & wirth & 115 & 139 & 152 & hirth & 117 \\
\hline keap & 103 & 119 & 134 & feap & 101 & gane & 90 & 127 & 148 & hane & 102 \\
\hline wunce & 148 & 168 & 177 & tunce & 159 & groe & 141 & 134 & 147 & broe & 134 \\
\hline grean & 118 & 127 & 141 & drean & 153 & durt & 109 & 122 & 136 & jurt & 122 \\
\hline ferm & 95 & 112 & 127 & serm & 101 & coad & 100 & 121 & 132 & doad & 100 \\
\hline reech & 120 & 140 & 156 & meech & 133 & fome & 118 & 124 & 135 & yome & 113 \\
\hline dait & 105 & 122 & 136 & yait & 108 & taip & 122 & 126 & 137 & baip & 116 \\
\hline ment & 76 & 96 & 117 & nent & 80 & keeze & 156 & 156 & 156 & veeze & 156 \\
\hline choyce & 162 & 173 & 184 & phoyce & 200 & berd & 100 & 121 & 137 & perd & 102 \\
\hline raize & 121 & 136 & 150 & kaize & 128 & leese & 121 & 138 & 153 & heese & 136 \\
\hline shooze & 165 & 164 & 170 & frooze & 170 & glew & 105 & 124 & 145 & plew & 111 \\
\hline thret & 165 & 142 & 143 & shret & 139 & burth & 133 & 137 & 153 & turth & 169 \\
\hline prufe & 146 & 161 & 192 & trufe & 162 & derth & 132 & 142 & 153 & kerth & 142 \\
\hline golph & 165 & 165 & 165 & tolph & 169 & binje & 153 & 166 & 184 & jinje & 184 \\
\hline boan & 95 & 116 & 133 & poan & 110 & turse & 114 & 130 & 149 & burse & 116 \\
\hline waik & 100 & 115 & 136 & haik & 107 & wead & 87 & 109 & 129 & gead & 98 \\
\hline mait & 98 & 113 & 131 & pait & 96 & hoest & 127 & 144 & 154 & hoert & 156 \\
\hline supe & 192 & 153 & 165 & zupe & 145 & stait & 120 & 127 & 147 & shait & 169 \\
\hline phocks & 138 & 152 & 166 & snocks & 123 & doun & 110 & 121 & 129 & loun & 98 \\
\hline pirl & 108 & 123 & 136 & birl & 107 & owt & 87 & 103 & 114 & ost & 112 \\
\hline coph & - & 140 & 149 & goph & 139 & helled & 120 & *202 & $* 226$ & helked & 193 \\
\hline fownd & 132 & 137 & 146 & yownd & 156 & flore & 136 & 144 & 154 & flove & 172 \\
\hline leest & 124 & 136 & 143 & heest & 156 & woak & 104 & 120 & 132 & woaf & 109 \\
\hline feal & 83 & 107 & 129 & beal & 85 & hoap & 107 & 125 & 139 & hoaj & 132 \\
\hline hoap & 107 & 125 & 139 & goap & 111 & boarn & 126 & 133 & 151 & boarm & 152 \\
\hline peece & 133 & 137 & 149 & deece & 156 & nyse & 154 & 161 & 168 & nyre & 177 \\
\hline blud & 110 & 122 & 135 & clud & 106 & cleen & 131 & 138 & 147 & cleem & 156 \\
\hline cheef & 122 & 131 & 147 & bleef & 148 & foart & 161 & 161 & 161 & loart & 162 \\
\hline dowt & 117 & 121 & 131 & kowt & 143 & hoald & 137 & 148 & 155 & hoalt & 156 \\
\hline surve & 119 & 135 & 149 & furve & 129 & breaz & 150 & 142 & 146 & brean & 152 \\
\hline braiv & 148 & 142 & 148 & brair & 216 & bote & 100 & 131 & 154 & boart & 134 \\
\hline boan & 95 & 116 & 133 & boam & 98 & boath & 180 & 159 & 161 & bost & 83 \\
\hline bern & 91 & 110 & 127 & berv & 113 & kamp & 96 & 106 & 128 & chak & 137 \\
\hline theem & 130 & 145 & 154 & theen & 131 & kase & 124 & 128 & 144 & chilm & 154 \\
\hline phlash & 181 & 181 & 181 & phlast & 171 & chare & - & 165 & 169 & chite & 140 \\
\hline swoar & 165 & 168 & 177 & swoam & 156 & chek & 130 & 131 & 141 & cish & 103 \\
\hline coalt & 121 & 129 & 147 & coaft & 134 & cherch & 150 & 158 & 168 & derd & 105 \\
\hline stroal & 145 & 153 & 164 & stroat & 169 & kost & 95 & 107 & 122 & drase & 148 \\
\hline soke & 111 & 136 & 149 & sofe & 160 & coart & 131 & 138 & 149 & famp & 90 \\
\hline seaks & 103 & 126 & 147 & seafs & 116 & drinc & 135 & 140 & 152 & fett & 104 \\
\hline bain & 88 & 108 & 127 & baps & 82 & fakt & 103 & 117 & 127 & flerch & 184 \\
\hline blote & - & 175 & 192 & blawnt & 171 & feer & 122 & 132 & 143 & fote & 111 \\
\hline busc & 124 & 123 & 132 & bont & 101 & philm & 144 & 141 & 151 & gare & 98 \\
\hline kelt & 89 & 109 & 131 & koez & 143 & phish & 163 & 163 & 167 & gat & 66 \\
\hline chaif & 127 & 135 & 148 & chote & 153 & phlat & 153 & 153 & 153 & grol & 117 \\
\hline
\end{tabular}


APPENDIX C (Continued)

\begin{tabular}{|c|c|c|c|c|c|c|c|c|c|c|c|}
\hline \multicolumn{4}{|c|}{ Pseudohomophones } & \multirow{2}{*}{\multicolumn{2}{|c|}{ Nonword Controls }} & \multicolumn{4}{|c|}{ Pseudohomophones } & \multirow{2}{*}{\multicolumn{2}{|c|}{ Nonword Controls }} \\
\hline & Mixed & PH 2nd & $\mathrm{PH} 1 \mathrm{st}$ & & & & Mixed & PH 2nd & PH 1st & & \\
\hline Item & GAS & IAS & SAS & Item & GAS & Item & GAS & IAS & SAS & Item & GAS \\
\hline klaps & 117 & 132 & 150 & klain & 126 & gaim & 110 & 122 & 138 & koop & 105 \\
\hline dawnt & 126 & 136 & 150 & doan & 102 & hoap & 107 & 125 & 139 & nol & 87 \\
\hline finc & - & 127 & 136 & fusc & - & mete & 193 & 151 & 162 & phek & 120 \\
\hline fers & 119 & 138 & 159 & fise & 120 & noze & 112 & 122 & 145 & phlur & 169 \\
\hline phret & 155 & 155 & 155 & phryve & 226 & plase & 138 & 140 & 155 & poan & 110 \\
\hline gaip & 111 & 122 & 138 & gelt & 88 & pryce & 155 & 165 & 181 & prud & 115 \\
\hline glene & - & 182 & 195 & glae & - & saif & 113 & 124 & 133 & serk & 105 \\
\hline groap & 119 & 131 & 148 & grok & 134 & sed & 75 & 95 & 114 & sheem & 155 \\
\hline hoan & 105 & 124 & 139 & haiv & 133 & skeme & 193 & 193 & 193 & shoath & 155 \\
\hline mame & 87 & 123 & 137 & mawg & 131 & shoan & 118 & 133 & 147 & skaje & 162 \\
\hline soke & 111 & 136 & 149 & sair & 118 & trane & 138 & 148 & 169 & troze & 144 \\
\hline skab & 102 & 118 & 139 & skoze & 202 & werk & 94 & 111 & 125 & weme & 159 \\
\hline shean & 117 & 137 & 154 & shoap & 146 & burth & 133 & 137 & 153 & lurth & 158 \\
\hline shail & 145 & 139 & 150 & shede & - & fayst & 130 & 147 & 154 & nayst & 132 \\
\hline snair & 158 & 161 & 176 & snue & - & fownd & 132 & 137 & 146 & nownd & 156 \\
\hline stich & 182 & 163 & 163 & staip & 135 & groope & 145 & 153 & 166 & moope & 135 \\
\hline strue & - & 161 & 166 & stralk & 171 & leest & 124 & 136 & 143 & deest & 156 \\
\hline shoarn & 180 & 180 & 180 & shype & 185 & looz & 120 & 122 & 129 & gooz & 135 \\
\hline thryve & 173 & 186 & $* 213$ & thryde & 226 & maik & 101 & 113 & 131 & daik & 118 \\
\hline trype & 156 & 171 & 193 & trean & 152 & milc & 110 & 119 & 128 & filc & 123 \\
\hline woez & 120 & 126 & 141 & wame & 89 & proov & 147 & 142 & 151 & troov & 147 \\
\hline berd & 100 & 121 & 137 & blait & 144 & shaip & 146 & 145 & 151 & traip & 137 \\
\hline blak & 107 & 125 & 138 & boap & 112 & tirn & 104 & 114 & 130 & nirn & 143 \\
\hline caik & 125 & 132 & 142 & & & & & & & & \\
\hline silc & - & 122 & 134 & & & & & & & & \\
\hline groov & 124 & 137 & 153 & & & & & & & & \\
\hline draip & 146 & 142 & 153 & & & & & & & & \\
\hline birn & 102 & 116 & 133 & & & & & & & & \\
\hline spayd & 145 & 144 & 155 & & & & & & & & \\
\hline raije & 132 & 142 & 153 & & & & & & & & \\
\hline bair & 113 & 128 & 144 & sair & 118 & & & & & & \\
\hline blud & 110 & 122 & 135 & brud & 120 & & & & & & \\
\hline bocks & 85 & 113 & 125 & vocks & 105 & & & & & & \\
\hline brane & 132 & 155 & 180 & prane & 169 & & & & & & \\
\hline cair & 110 & 125 & 144 & gair & 118 & & & & & & \\
\hline dait & 105 & 122 & 136 & nait & 105 & & & & & & \\
\hline deigh & 151 & 162 & 177 & teigh & 151 & & & & & & \\
\hline faice & 140 & 152 & 165 & gaice & 169 & & & & & & \\
\hline gaim & 110 & 122 & 138 & raim & 114 & & & & & & \\
\hline gole & 106 & 133 & 150 & jole & 96 & & & & & & \\
\hline hed & 72 & 91 & 111 & gled & 96 & & & & & & \\
\hline heet & 97 & 115 & 130 & breet & 127 & & & & & & \\
\hline hoam & 108 & 124 & 140 & goam & 102 & & & & & & \\
\hline keap & 103 & 119 & 134 & meap & 100 & & & & & & \\
\hline reech & 120 & 140 & 156 & feech & 127 & & & & & & \\
\hline weel & 87 & 107 & 126 & beel & 92 & & & & & & \\
\hline tair & 115 & 125 & 144 & & & & & & & & \\
\hline
\end{tabular}


APPENDIX C (Continued)

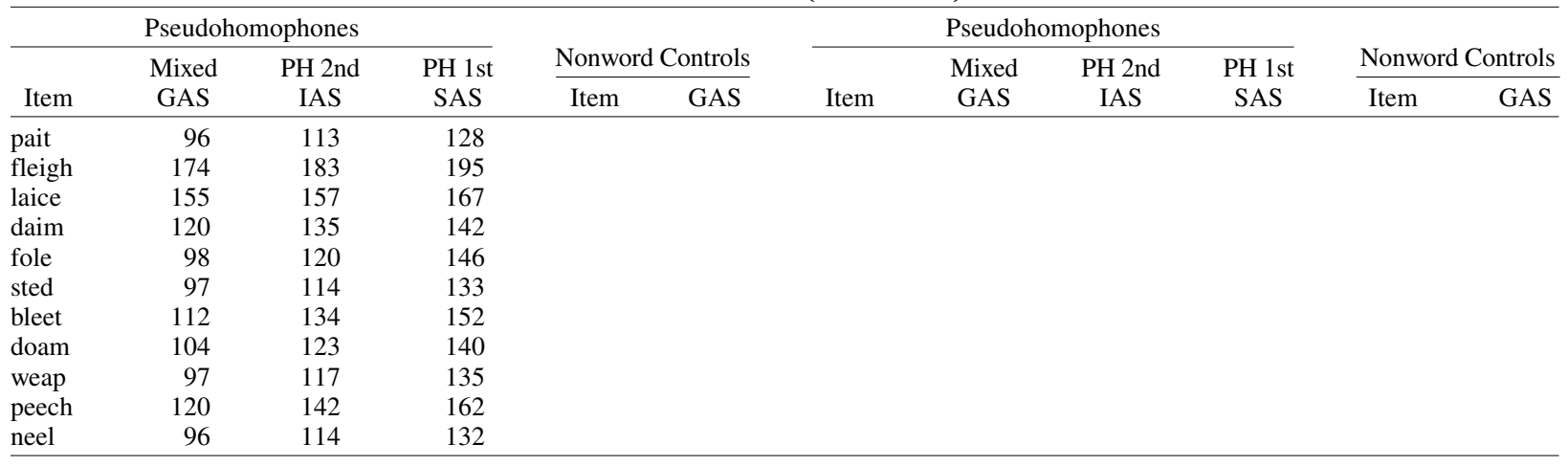

Note-There are unequal numbers of pseudohomophones and nonwords because Herdman, LeFevre, and Greenham (1996) used twice as many pseudohomophones as nonword controls. Dashes indicate items read incorrectly by the DRC model. * Items excluded from the base word frequency analysis.

\section{APPENDIX D}

Cycles to Reading Aloud Criterion for Weekes's (1997) Items With the GAS Parameter Set

\begin{tabular}{lrlrllll}
\hline seb & 84 & shub & 109 & skown & 142 & slanch & 149 \\
sep & 81 & sket & 108 & slort & 120 & snutch & 168 \\
som & 81 & sneg & 120 & sorch & 133 & spants & 133 \\
ped & 74 & pand & 86 & plown & 126 & pretch & 189 \\
pob & 73 & prib & 111 & prish & 146 & pruise & 142 \\
sab & 76 & sarn & 99 & shart & 107 & shrain & 177 \\
tha & 166 & thun & 93 & thurn & 130 & threwn & 140 \\
tob & 72 & tord & 91 & trabe & 146 & tranks & 119 \\
wid & 75 & wilk & 97 & whurf & 141 & whetch & 199 \\
sov & - & spuk & 134 & spont & 125 & squate & 248 \\
spo & 141 & stul & 117 & steck & 101 & stetch & 171 \\
sut & 71 & sush & 92 & swonk & 142 & sworve & 148 \\
lud & 83 & leck & 86 & lorge & 116 & loaked & 116 \\
cag & 72 & cade & 95 & carge & 117 & clants & 122 \\
cas & 80 & clet & 110 & cland & 122 & clitch & 175 \\
cif & 131 & colm & 116 & crand & 114 & clotch & 168 \\
bam & 75 & blog & 102 & betch & 113 & branks & 118 \\
bez & 94 & blug & 105 & blent & 122 & brants & 128 \\
bot & 66 & bram & 92 & brant & 110 & breeth & 150 \\
gid & 78 & gand & 91 & grink & 146 & granks & 137 \\
gop & 74 & gend & 84 & grite & 176 & grewth & 151 \\
hin & 70 & hant & 86 & horch & 128 & hupped & 153 \\
cug & 75 & crum & 109 & crish & 126 & crants & 123 \\
fot & 69 & frip & 103 & frosh & 146 & flanch & 146 \\
fud & 83 & fune & 154 & frund & 127 & fretch & 233 \\
\hline Note & & & & & & &
\end{tabular}

Note-A dash indicates items read incorrectly by the DRC model. 


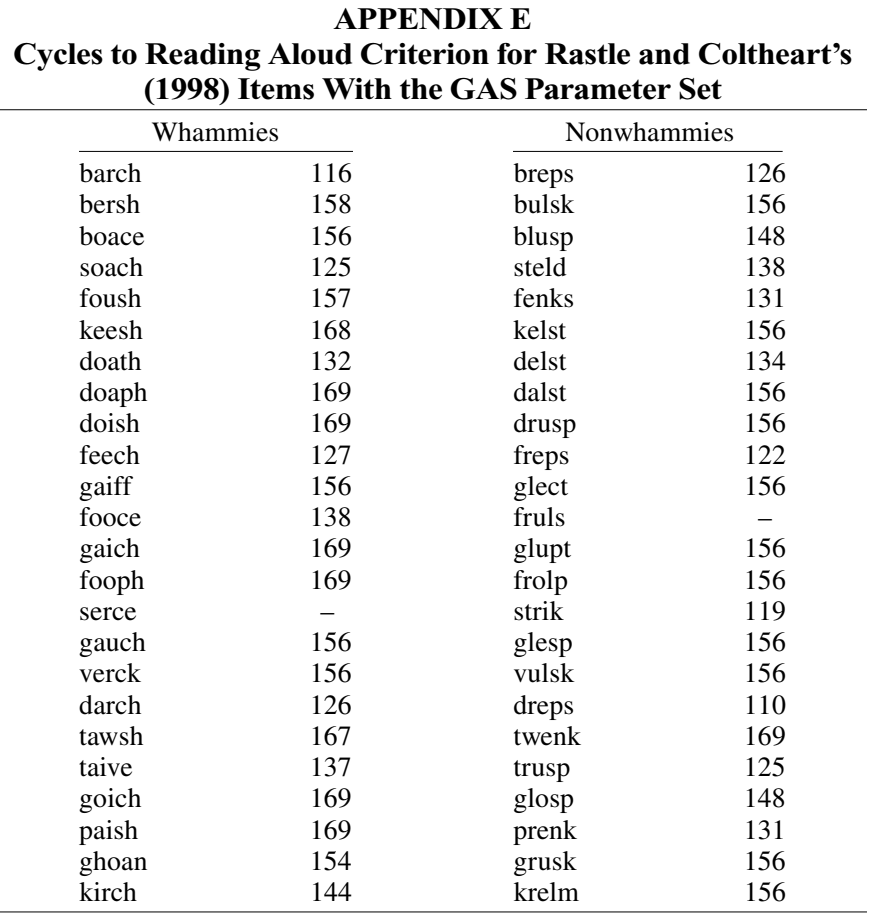

Note-A dash indicates items read incorrectly by the DRC models. The item fruls was excluded from the present analysis because it has a late position whammy in the DRC model. 
APPENDIX F

Cycles to Reading Aloud Criterion for Reynolds and Besner's (2004) Items With the GAS Parameter Set

\begin{tabular}{|c|c|c|c|}
\hline \multicolumn{2}{|c|}{ High N } & \multicolumn{2}{|c|}{ Low N } \\
\hline bant & 94 & bapt & 112 \\
\hline dast & 83 & dakt & 120 \\
\hline dend & 84 & demf & 120 \\
\hline dest & 76 & demk & 121 \\
\hline dind & 87 & dild & 104 \\
\hline dunt & 85 & dund & 110 \\
\hline fant & 88 & fapt & 104 \\
\hline fent & 76 & femp & 115 \\
\hline fest & 77 & fenf & 134 \\
\hline fint & 87 & fimk & 122 \\
\hline fost & 85 & fomp & 114 \\
\hline fust & 83 & fuld & 107 \\
\hline hant & 86 & hamf & 118 \\
\hline hend & 79 & hemk & 118 \\
\hline hest & 79 & hept & 105 \\
\hline hust & 81 & himp & 100 \\
\hline kest & 85 & kect & 113 \\
\hline kint & 88 & kimp & 113 \\
\hline lant & 90 & $\operatorname{lamf}$ & 107 \\
\hline lind & 84 & $\operatorname{limf}$ & 121 \\
\hline lond & 93 & lomk & 121 \\
\hline lont & 92 & lonf & 122 \\
\hline mant & 92 & mamk & 110 \\
\hline nast & 86 & nald & 125 \\
\hline nent & 80 & nant & 102 \\
\hline pont & 93 & pomk & 115 \\
\hline pust & 80 & pumk & 107 \\
\hline rast & 81 & ramf & 135 \\
\hline rint & 87 & rild & 102 \\
\hline sant & 92 & samf & - \\
\hline sast & 83 & samk & 108 \\
\hline sest & 78 & semp & 111 \\
\hline sint & 85 & simk & 121 \\
\hline sunt & 93 & suld & 113 \\
\hline sust & 88 & sumf & 111 \\
\hline $\tan t$ & 90 & $\operatorname{tamf}$ & - \\
\hline tast & 81 & timp & 99 \\
\hline tind & 87 & timk & 128 \\
\hline tunt & 89 & tuld & 119 \\
\hline tust & 83 & tunf & 117 \\
\hline wint & 83 & wimf & 143 \\
\hline wust & 85 & wund & 99 \\
\hline
\end{tabular}

Note-Dashes indicate items read incorrectly by the DRC model.

(Manuscript received July 15, 2003;

revision accepted for publication October 14, 2004.) 